\title{
Sensitivity of a regional climate model on the simulation of high intensity rainfall events over the Arabian Peninsula and around Jeddah (Saudi Arabia)
}

\author{
Mansour Almazroui
}

Received: 3 August 2010 / Accepted: 10 December 2010/Published online: 8 January 2011

(C) Springer-Verlag 2011

\begin{abstract}
As a step towards the adoption and use of the regional climate model (RegCM3) for the simulation of intense rainfall events over the Arabian Peninsula, this study examines its sensitivity to domain size, boundary location, forcing fields, and resolution. In the climatological results, RegCM3 performs well in reproducing the annual and the seasonal mean precipitation as well as the contrast between wet and dry years in terms of the amounts and locations of the rainbands. In addition, simulations are performed for two cases of intense rainfall events in the Jeddah area and surroundings using a combination of three domains and two boundary forcings at $50 \mathrm{~km}$. The results show that different combinations of these parameters provide different skills for the regional model. However, RegCM3 performs relatively better when ERA40 (NNRP2) is used at the boundaries in the smaller domain (larger domain), indicating the importance of the stronger (relatively weaker) influence of boundary forcing needed to capture these intense rainfall events around Jeddah. This may be explained by the fact that around that region, RegCM3 produces, in the smaller domain, higher relative humidity and stronger wind vectors closer to the reanalyses when nested within the ERA40, while it shows its best performance with the larger domain when driven by NNRP2. It is also shown that the use of high resolution does not systematically improve the simulation of such events, although some encouraging results were produced.
\end{abstract}

\footnotetext{
M. Almazroui ( $\bowtie)$

Center of Excellence for Climate Change Research,

Department of Meteorology,

King Abdulaziz University,

P. O. Box 80234, Jeddah, Saudi Arabia

e-mail: mansour@kau.edu.sa
}

\section{Introduction}

The rainfall in most parts of Saudi Arabia is scant, irregular, and unreliable, falling generally from October through April (Atlas 1984). During all other months, there is almost no rainfall except in the south-western areas of the country (Almazroui 2010). Due to mountainous areas, the spatial variation of the rainfall in the south-western region is high. This area is climatologically different from the rest of the country. It is characterized by precipitation events throughout the whole year because of the topographically driven convective rain (Al-Mazroui 1998; Abdullah and AlMazroui 1998). The annual total rainfall in the north of this area, particularly in Jeddah $\left(21.71^{\circ} \mathrm{N}, 39.18^{\circ} \mathrm{E}\right)$, ranges from 50 to $100 \mathrm{~mm}$, occurring mainly during the winter season. In general, only a few rainfall events are sufficient to produce this amount in this semi-arid region (Köppen 1936).

The area's flash flooding is mainly due to convective storm-related events, which can cause a great deal of damage in arid and semi-arid regions such as Saudi Arabia. Several devastating flash floods have recently occurred (e.g., on 25 November 2009 at Jeddah and on 5 May 2010 at Riyadh, among many others), suggesting a strong need to emphasize research aimed at improving extreme rainfall prediction. Reliable predictions of extreme rainfall events remain a difficult challenge for numerical modelers. The tools for an accurate prediction of high-impact weather, such as severe thunderstorms and heavy rainfall events (Litta et al. 2007) that may cause flash flooding, include regional climate models.

Recently, regional climate models (RCMs) have become a useful tool for downscaling global climate simulations and/or reanalysis providing regional climate details when nested within the boundaries of such global datasets for regional climate studies (Giorgi et al. 1994; Leung et al. 


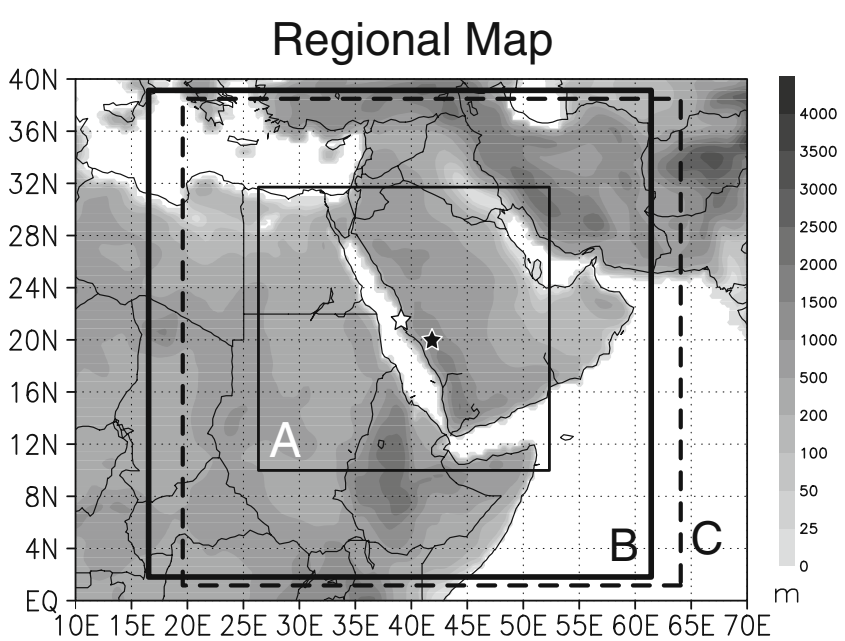

Fig. 1 The model domains and topography (in meters). The inner domain with thin solid lines is domain A $(60 \times 60$ grid point $)$, the larger domain with bold solid lines is domain $\mathrm{B}(92 \times 108$ grid point), both centering at $21^{\circ} \mathrm{N}$ and $39^{\circ} \mathrm{E}$ (open asterisk). The last one with dashed lines is domain $\mathrm{C}(92 \times 108$ grid point $)$ centering at $20^{\circ} \mathrm{N}$ and $42^{\circ} \mathrm{E}$ (closed asterisk)

1999; Sylla et al. 2009). In this approach, domain size and the location of lateral boundaries, resolution, and the quality of the forcing fields have a strong impact in the simulations produced by the regional model. In fact, earlier studies have shown the importance of these parameters in such simulations. Jones et al. (1995) argued that the regional domain must be large enough to allow the full development of fine-scale features over the region. In the same vein, Seth and Giorgi (1998) showed that the lateral boundaries must be placed well outside the region of interest to avoid an unrealistic response to internal forcings, while a smaller domain confines the interior solution more toward the coarse driving fields, which may also yield an unrealistic response to internal higher resolution forcing (Giorgi and Mearns 1999). In addition, Nobre et al. (2001) noted that their simulations were sensitive to both the model resolution and the location of the lateral boundaries, while Shiao and Juang (2006) demonstrated that the simulated large-scale circulation and rainfall distribution are more sensitive to the domain size than to the horizontal resolution. Recently, Sylla et al. (2010) argued that the use of better reanalyses at the boundaries in their relatively large domain might have contributed to improving their simulations. From this discussion, it is clearly apparent that domain size, the location of lateral boundaries, the resolution considered, and also the quality of the forcing fields are of critical importance for the performance of the regional climate model.

Therefore, to adopt the RegCM3 for the simulation of rainfall events in and around Jeddah, its sensitivity to all those parameters has to be addressed. Towards this goal, the objective of this study is to assess the capability of RegCM3 to reproduce specific cases of intense rainfall events in and around Jeddah (Saudi Arabia) by examining its sensitivity to the domain size, the location of lateral boundaries, the resolution, and also the quality of the forcing fields. The next section begins with the model description and simulations.

\section{Data and methodology}

\subsection{Model description}

The International Centre for Theoretical Physics (ICTP) Regional Climate Model, RegCM3 (Giorgi et al. 1993a, b; Pal et al. 2007), is used in this study. RegCM3 is a primitive equation, sigma vertical coordinate model based on the hydrostatic dynamical core of the NCAR/PSU's mesoscale meteorological model MM5 (Grell et al. 1994). Radiation is represented by the CCM3 parameterization of Kiehl et al. (1996) and the planetary boundary layer scheme is by Holtslag et al. (1990). Interactions between the land surface and the atmosphere are described using the Biosphere Atmosphere Transfer Scheme (BATS1E; Dickinson et al. 1993). The scheme of Zeng et al. (1998) is used to represent fluxes from water surfaces. Convective precipitation is calculated with the scheme of Grell (1993) applying the Fritsch and Chappell (1980) closure assumption. Resolvable precipitation processes are treated with the subgrid explicit moisture scheme (SUBEX) of Pal et al.
Table 1 The summary of all simulations performed and their names

\begin{tabular}{ll}
\hline Experiment names & Description \\
\hline ERA40-RegCM_A50 & RegCM3 driven by ERA40 in domain A at $50 \mathrm{~km}$ \\
ERA40-RegCM_A25 & RegCM3 driven by ERA40 in domain A at $25 \mathrm{~km}$ \\
ERA40-RegCM_B50 & RegCM driven by ERA40 in domain B at $50 \mathrm{~km}$ \\
ERA40-RegCM_C50 & RegCM driven by ERA40 in domain C at $40 \mathrm{~km}$ \\
NNRP2-RegCM_A50 & RegCM3 driven by NNRP2 in domain A at $50 \mathrm{~km}$ \\
NNRP2-RegCM_A25 & RegCM3 driven by NNRP2 in domain A at $25 \mathrm{~km}$ \\
NNRP2-RegCM_B50 & RegCM3 driven by NNRP2 in domain B at $50 \mathrm{~km}$ \\
NNRP2-RegCM_C50 & RegCM3 driven by NNRP2 in domain C at $50 \mathrm{~km}$ \\
\hline
\end{tabular}


(2000), which is a physically based parameterization including subgrid scale cloud fraction, cloud water accretion, and evaporation of falling raindrops.

RegCM3 has been used for a wide range of applications (e.g., Pal et al. 2007), including regional climate change (e.g., Giorgi et al. 2004; Diffenbaugh et al. 2005), water resources (e.g., Pal et al. 2000), and seasonal prediction (e.g., Rauscher et al. 2006; Seth et al. 2007), but it has also been used to study specific cases of meteorological events (e.g., Zakey et al. 2006; Yuan et al. 2008; Santese et al. 2010; Camara et al. 2010; Tchotchou and Kamga 2010). In that same vein, RegCM3 is used for the simulation of some case studies of high intensity rainfall events occurring over the Arabian Peninsula and more specifically over Jeddah and its surroundings. In particular, we have studied the effect of domain size and the (strong and weak) influence of boundary forcings on the performance of such a model to capture those events.
Fig. 2 The spatial distribution of rainfall climatology simulated for NNRP2-RegCM (left) averaged over 1998-2009 (a, c, e). The rainfall (millimeter) obtained from the TRMM data averaged over 1998-2009 is shown in the right panels $(\mathbf{b}, \mathbf{d}, \mathbf{f})$ a) RegCM_B50 Annual Rainfall 1998-2009

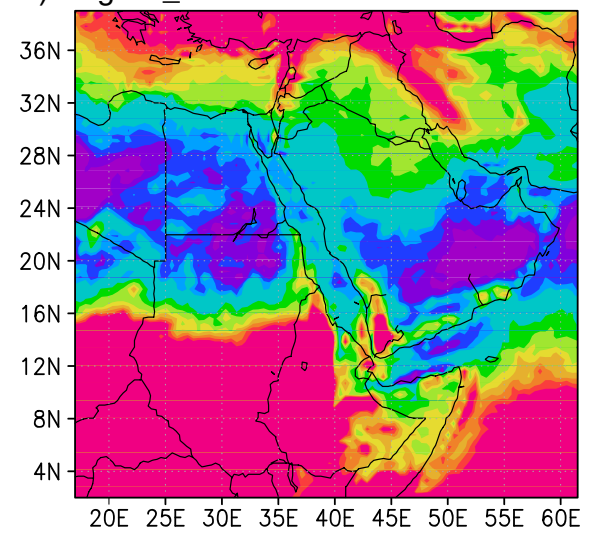

c) RegCM_B50 Wet Season Rainfall 1998-2009

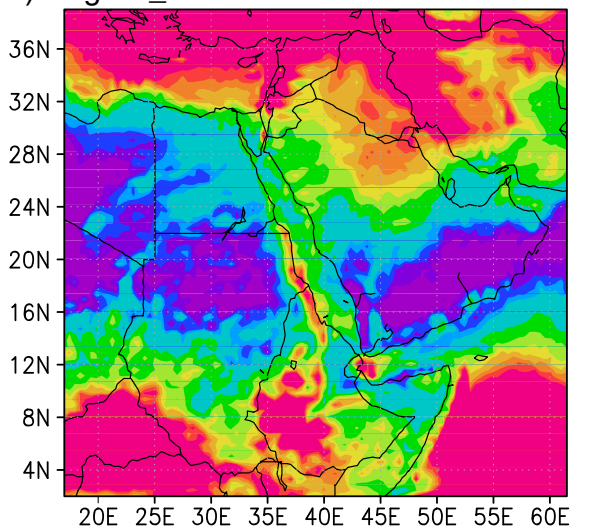

e) RegCM_B50 Dry Season Rainfall 1998-2009

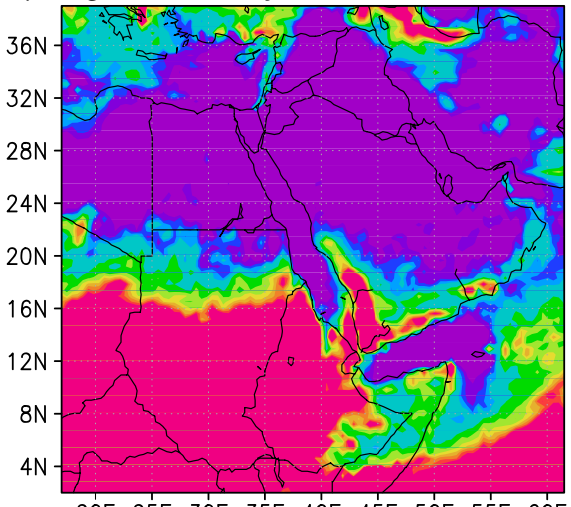

20E 25E 30E 35E 40E 45E 50E 55E 60E

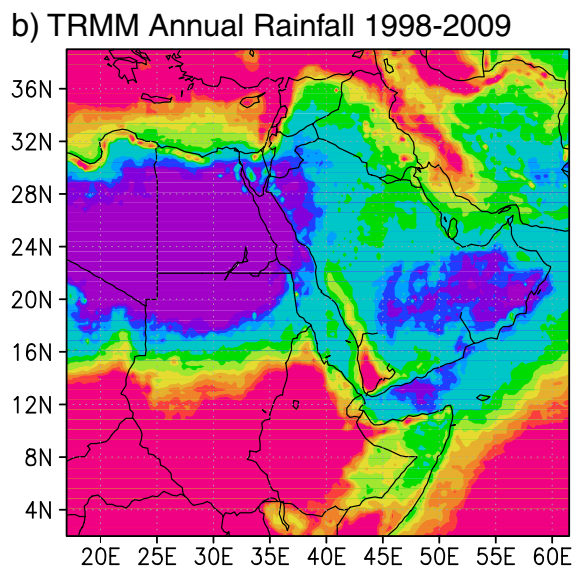

d) TRMM Wet Season Rainfall 1998-2009

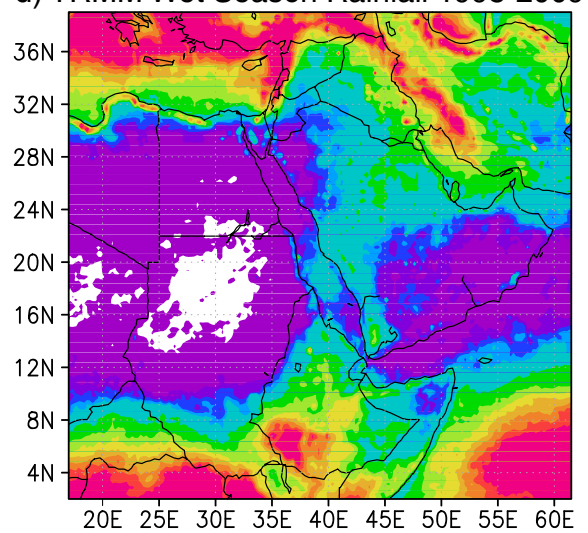

f) TRMM Dry Season Rainfall 1998-2009

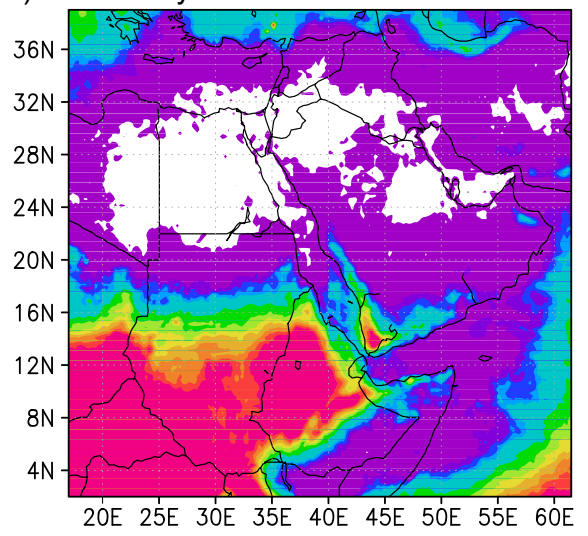

$20 \quad 30 \quad 40 \quad 50 \quad 100 \quad 150 \quad 200 \quad 250 \quad 300 \quad 350 \quad 400$

$\mathrm{mm}$ 
Fig. 3 The time sequences of rainfall climatology obtained from observations (black bar), the TRMM (lightly shaded bar), and simulation for NNRP2RegCM (open bar) averaged over Saudi Arabia. The mean is the rainfall averaged over 1998-2009

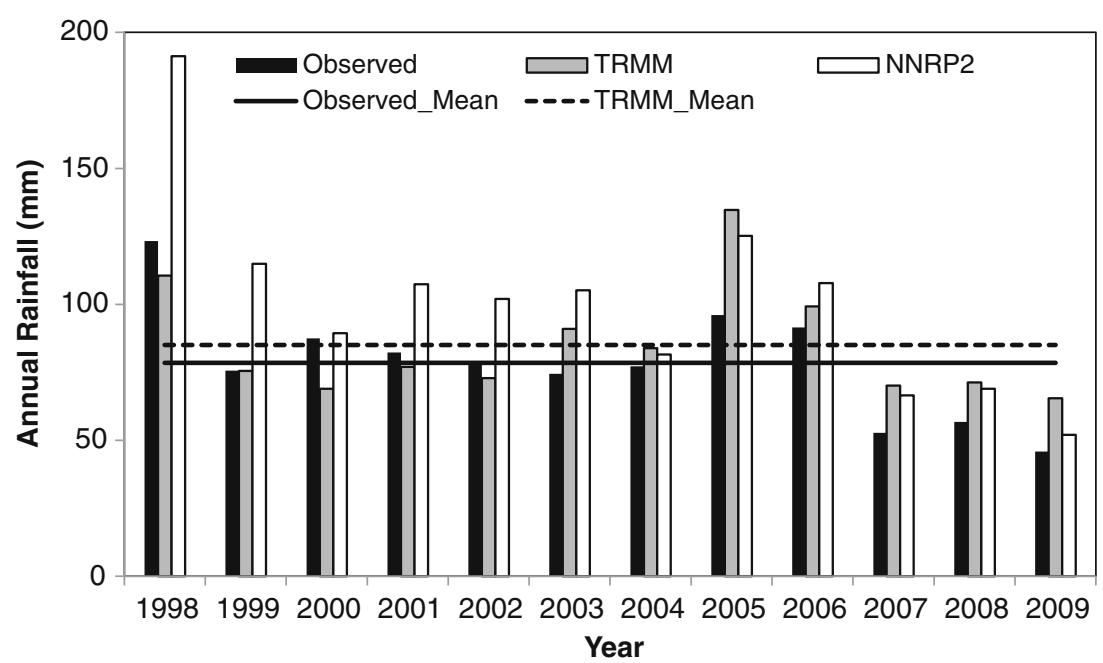

\subsection{Experimental design and data}

To explore the sensitivity of the regional climate model RegCM3 in capturing high intensity rainfall events over
Jeddah, simulations at $50 \mathrm{~km}$ resolution were conducted using three different domains (A, B, and C). Note that domains $\mathrm{A}$ and $\mathrm{B}$ have the same center. Domains $\mathrm{B}$ and $\mathrm{C}$ are of the same size, but the center is slightly shifted towards the southeast in $\mathrm{C}$, as
Fig. 4 The spatial distribution of annual rainfall (millimeter) simulated for NNRP2-RegCM (left) for 2006 (a) and 2007 (c). The annual rainfall (millimeter) obtained from the TRMM data averaged for 2006 (b) and 2007 (d) is shown in the right panels a) NNRP2-RegCM_B50 Annual Rainfall 2006

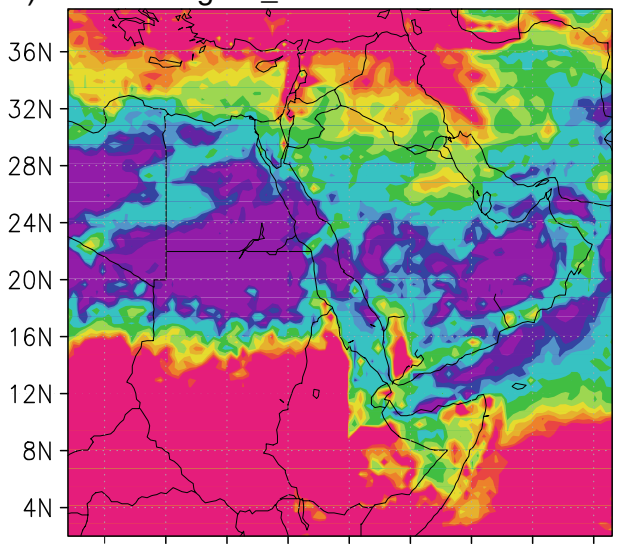

20E 25E 30E 35E 40E 45E 50E 55E 60E

c) NNRP2-RegCM_B50 Annual Rainfall 2007

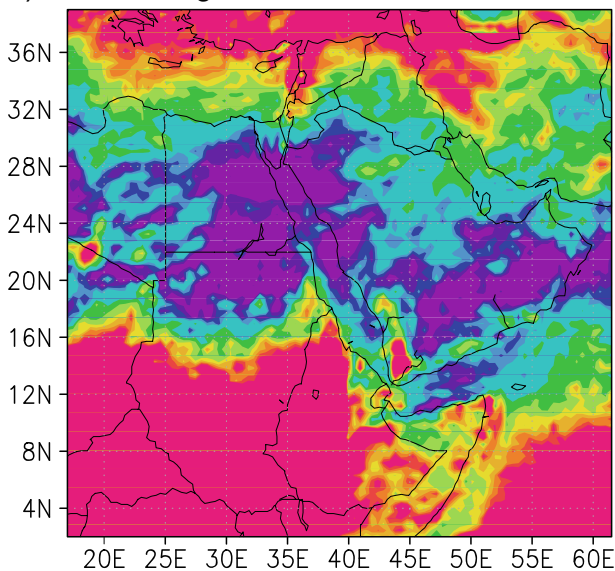

b) TRMM Annual Rainfall 2006

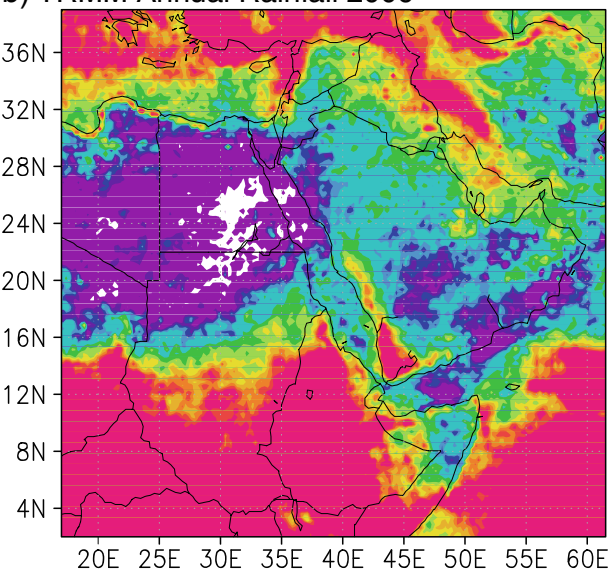

d) TRMM Annual Rainfall 2007

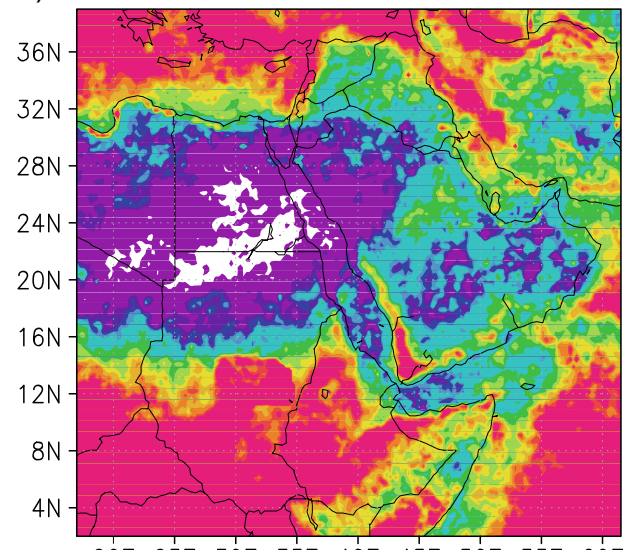

20E 25E 30E 35E 40E 45E 50E 55E $60 \mathrm{E}$ $\mathrm{mm}$ 
shown in Fig. 1. Note that the domains presented here are interior domains, where the 15 grid points of the buffer are already removed. This domain sensitivity study will help to determine whether strong or weak constraints of the boundary forcings are needed to capture those events. It will also permit addressing the implications of the location of lateral boundaries in the simulation of such events. Sensitivity experiments are also performed at $25 \mathrm{~km}$ resolution to investigate the relative role of high resolution in improving the simulations of high intensity rainfall events around Jeddah.

Model initial and lateral boundary conditions were created using two reanalyses, which are NNRP2 (Kalnay et al. 1996; Kistler et al. 2001) and ERA40 (Uppala et al. 2005) at the $2.5^{\circ} \times 2.5^{\circ}$ gridded and 6-hourly temporal resolution. These data, which are derived from various observational sources including rawinsondes, surface marine data, aircraft data, surface land synoptic data, satellite sounder data, special sensing microwave imager, and satellite cloud drift winds, are interpolated onto the model grid and used in the corresponding simulations.

Sea surface temperature (SST), used to force RegCM3 (in all cases), is obtained from the National Oceanic and Atmospheric Administration Optimum Interpolation (OI) SST. This OISST analysis is produced weekly on a $1^{\circ}$ grid. These analyses were based on ship and buoy SST data supplemented with satellite SST retrievals. OISST is the most updated observed SST field and it resolves equatorial upwelling and fronts (Reynolds and Smith 1994; Reynolds et al. 2002, 2007).

The regional climate model performance was first evaluated from the climatological point of view (19982009), at the annual and seasonal timescales as well as for wet and dry years, using the NNRP2 reanalysis over the large Arabian Peninsula domain before focusing on some targeted rainfall events for the sensitivity study. To reinforce the results, two events have been considered for this sensitivity study. They occurred on 8 January 1999 and 31 December 2001. The simulations for the former and latter cases began on 1 October 1998 and 1 September 2001, respectively, and were completed for 5 months in order to place the results in a broader perspective. For more convenience, the summary of all simulations performed and their names are shown in Table 1.

The focus of this paper is to study the effect of domain size and the (strong and weak) influence of lateral boundary forcings on the performance of RegCM3 in capturing the high intensity rainfall events occurring over the Arabian Peninsula and more specifically over Jeddah and its surroundings.

\section{Results}

The degree to which the regional climate model simulates mean rainfall climatology over the Arabian Peninsula has to be examined before assessing its performance in order to capture the specific cases of intense rainfall events occurring in the region under different configurations.

\subsection{Mean rainfall climatology}

Figure 2 shows the 12-year (1998-2009) annual average of mean precipitation for RegCM3 and TRMM (Fig. 2a and b, respectively) and their seasonal means (Fig. 2c, $d$ for the wet season; e, f for the dry season). Throughout the year, TRMM reveals the larger amounts of precipitation in the northern and southern parts of the peninsula and reveals that the regions in the southeast of the domain are predominantly dry. The regional climate model captures the locations of these greater and lesser amounts of precipitation but shows some overestimation in the northern regions. The model's overestimations are more significant during the wet season (compared to the TRMM observations, which have almost the same distribution as the annual mean, except that the rainfall amounts are lower in the southern regions, and the areas covered by dry conditions are more extended). In the dry season, rainfall is only confined to the southern regions along the coastlines in the observations; the regional model captures this fairly well although it tends to extend slightly northward.

In general, RegCM3 shows a fairly good performance in representing the rainfall climatology over the Arabian Peninsula; however, it has a tendency to exhibit consistently larger amounts, compared to TRMM, in regions experiencing wetter conditions. It is thus worth investigating how well it performs during wet and dry years.

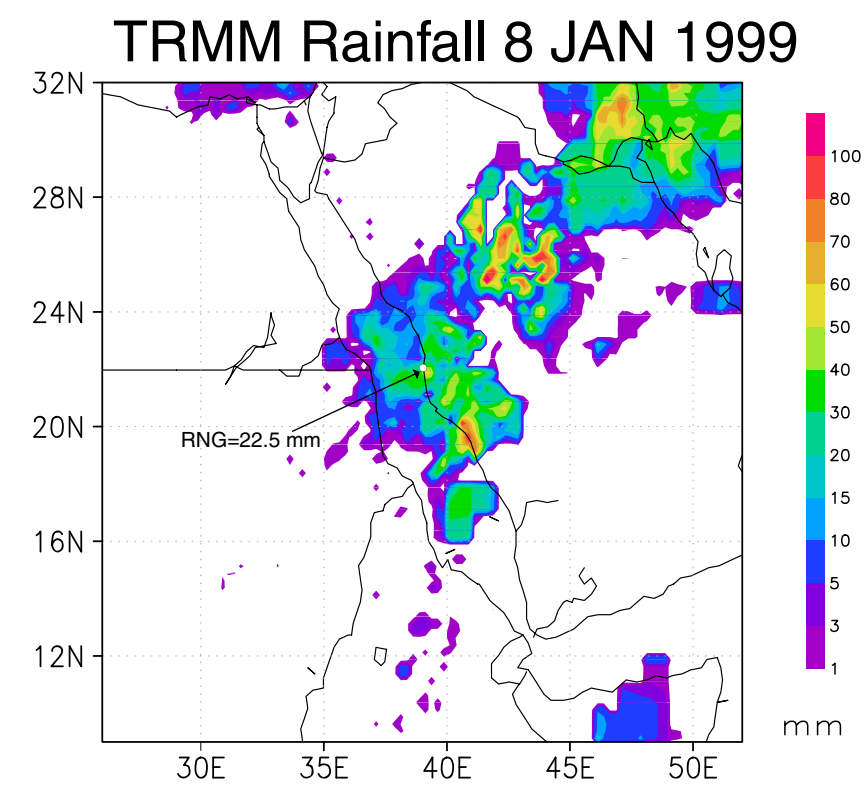

Fig. 5 The spatial distribution of daily rainfall (millimeter) obtained from the TRMM data on 8 January 1999. The rain gauge $(R N G)$ recorded amount $(22.5 \mathrm{~mm})$ at Jeddah (white dot) 


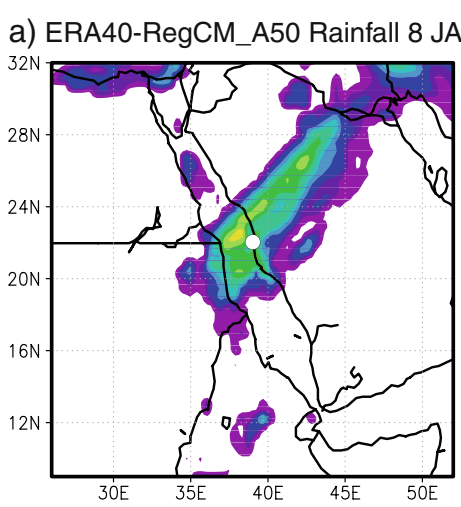

d) NNRP2-RegCM_A50 Rainfall 8 JAN 1999

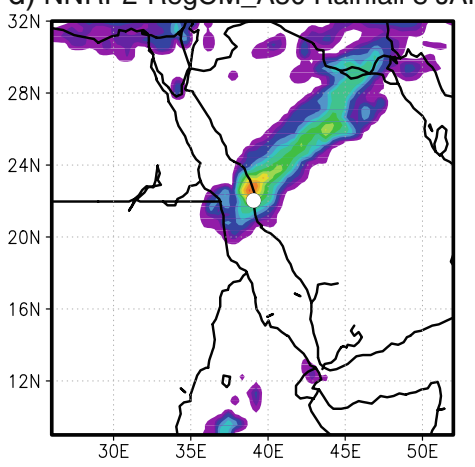

b) ERA40-RegCM_B50 Rainfall 8 JAN 1999

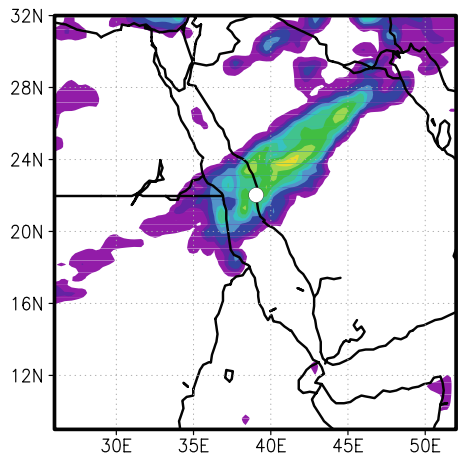

e) NNRP2-RegCM_A50 Rainfall 8 JAN 1999

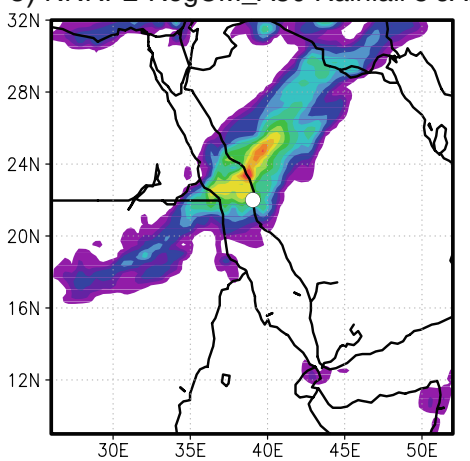

c) ERA40-RegCM_C50 Rainfall 8 JAN 1999

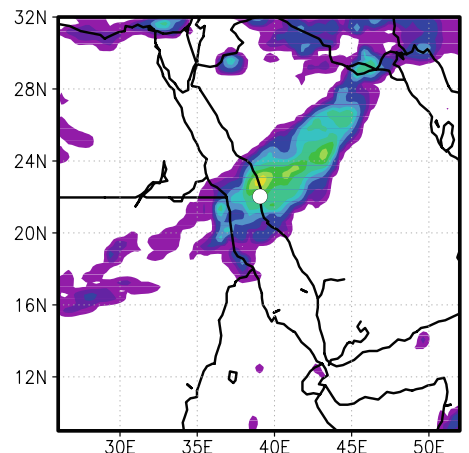

f) NNRP2-RegCM_A50 Rainfall 8 JAN 1999

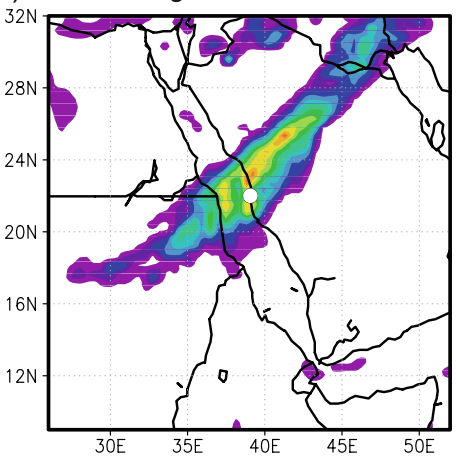

$\mathrm{mm}$

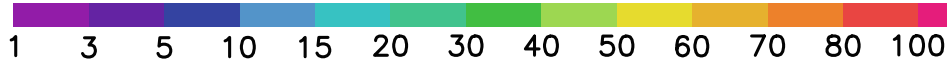

Fig. 6 The spatial distribution of daily rainfall (millimeter) on 8 January 1999 simulated by the RegCM3 forced by ERA40 (upper panels, a-c) and NNRP2 (lower panels, d-f) for domain A (left

We first discriminate the wet and dry years by plotting the interannual variability of precipitation using three different products averaged over the whole region: NNRP2, TRMM, and the entire rain-gauge network of the peninsula (Fig. 3). Evidently, all the three products display similar variability and the two consecutive years in which the rainfall shows opposite behavior are 2006 (above the mean) and 2007 (below the mean). We, therefore, consider them as examples of wet and dry years, respectively, and evaluate the regional climate model's performance during these contrasting years.

Figure 4 shows the annual mean rainfall from RegCM3 and TRMM for 2006 (Fig. 4a and b, respectively) and 2007 (Fig. 4c and d, respectively). During the wet year, TRMM distribution is not very different from the mean climatology discussed in Fig. 2. The regional model, in turn, shows generally and substantially higher rainfall intensity in the northern regions but also along the coastlines adjacent to the Indian Ocean, hence shifting the areas of dry conditions inland. These wet conditions not present in the TRMM observation may have resulted from the ascent of humid air, which may have occurred at the interface between the land and sea in the regional panels), domain B (middle panels), and domain C (right panels). The location of Jeddah is shown by the white dot

model. For the dry year, both TRMM and RegCM3 exhibit the maxima of rainfall mainly in the center of the Arabian Peninsula and along coastlines adjacent to the Red Sea and the Indian Ocean. However, the regional model shifts the rainfall maximum situated in the central domain further north and, in addition, shows larger areas of dry conditions.

Overall, RegCM3 is capable of reproducing the annual and the seasonal mean climatology of precipitation over the Arabian Peninsula as well as the contrast between wet and dry years in terms of the amounts and locations of the rainbands. From this analysis, it is evident that over the Arabian Peninsula, observed rainfall amounts are very low, mostly less than $200 \mathrm{~mm} /$ year $(0.55 \mathrm{~mm} /$ day $)$ for the annual mean climatology and less than $250 \mathrm{~mm} /$ year $(0.68 \mathrm{~mm} /$ day $)$ for the wet year. Only some small areas located at the interface between the Red Sea and Indian Ocean experience the larger rainfall amounts, exceeding sometimes $400 \mathrm{~mm} /$ year $(1.09 \mathrm{~mm} /$ day $)$. Due to these very low amounts over most of these regions, this study relating to precipitation climatology over the Arabian Peninsula may provide only a limited understanding of the phenomena. Therefore, a more fruitful investigation should examine targeted specific cases of the 
high intensity rainfall events that occur in the regions once in a while and that cause a great deal of damage. In addition, it is clear that the regional model has a tendency to overestimate the maxima and to extend areas of dry conditions, hence confining the higher amounts to some localized regions. It is thus a good tool for studying those specific cases of high intensity rainfall events striking the region.

The first case examined is the one of 8 January 1999. On that day, the rain gauge recorded $22.5 \mathrm{~mm}$ rain at Jeddah $\left(21.71^{\circ} \mathrm{N} ; 39.18^{\circ} \mathrm{E}\right)$. The location of the rain gauge at Jeddah is very close to the center of domain A, as shown by the open asterisk in Fig. 1. The spatial distribution of rainfall obtained from the TRMM data (Fig. 5) shows rainfall in a tilted (towards the north) band and displays maxima at the center of the Arabian Peninsula and along the Red Sea coastline south of Jeddah. The TRMM data also indicate about $30 \mathrm{~mm}$ of rainfall nearby Jeddah. The simulation of this rain event using different model domains and driving forces is now discussed.

\subsection{Sensitivity to boundary location and forcing}

The spatial distributions of daily rainfall (millimeter) simulated by the RegCM3 with ERA40 (top panels) and NNRP2 (bottom panels) for domain A (left panels), domain $\mathrm{B}$ (middle panels), and domain $\mathrm{C}$ (right panels) are displayed in Fig. 6, respectively. All the simulations over the three domains show almost the same patterns of rainfall distribution as those obtained from the TRMM on 8 January 1999 (Fig. 5); however, the rainband is narrower. The maximum rainfall is located in the center of the Arabian Peninsula for all cases. The rainfall maxima provided by ERA40-RegCM in all domains is lower compared to the same from NNRP2-RegCM. In fact, the latter found the rainfall maxima around the coastlines but shifted them further north. Nevertheless, the ERA40-RegCM_A50 and NNRP2-RegCM_B50 produced encouraging results, as the rainband was thicker than in other cases and closer to TRMM rainfall spatial distribution.

As we are concerned with the rainfall event around Jeddah for that particular day, to quantify the simulated rainfall amount when RegCM3 is driven by ERA40 and NNRP2, the model output for the three domains were extracted near Jeddah station (closest grid point) and compared with the observed data. The simulated rainfall on 8 January 1999 for all the three domains and the two boundary forcings are displayed in Fig. 7. The rain gauge and the TRMM data confirmed the occurrence of large rainfall events on 8 January 1999 in Jeddah, as seen from the bar plot, where the day after (and furthermore the day before) shows very low rainfall intensity. Out of the three domains and the two boundary forcings applied for each domain, the peak rainfalls for domains $\mathrm{A}$ and $\mathrm{B}$ with both driving large-scale

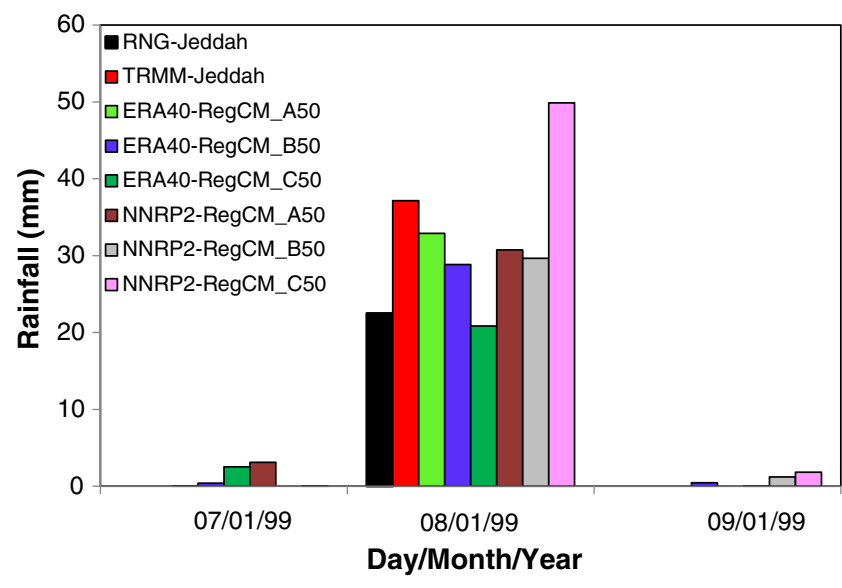

Fig. 7 Bar graph plot of the daily rainfall (millimeter) during 7-9 January 1999 recorded by the rain gauge $(R N G)$ at Jeddah, observed by TRMM and simulated by RegCM3 forced by ERA40 and NNRP2 over different domains (A, B, and C) extracted near Jeddah station

fields fall within the TRMM and rain gauge precipitation amounts. In addition, RegCM3 appears to be more sensitive to domain size when driven by ERA40 rather than NNRP2. Nevertheless, the rainfall peaks for all the four cases (ERA40-RegCM_A50, ERA40-RegCM_B50, NNRP2RegCM_A50, and NNRP2-RegCM_B50) are very close and comparable to the TRMM observations and the rain gauge data (Fig. 7).

Next, an assessment of the sensitivity of the model to domain choice and boundary forcing in simulating another high intensity rainfall event occurring on 31 December 2001 was undertaken. The rain gauge recorded $25 \mathrm{~mm}$ rainfall at Jeddah. The spatial distribution of TRMM rainfall (Fig. 8) shows a similarity to previous patterns. In fact, the rainfall is confined in a tilted

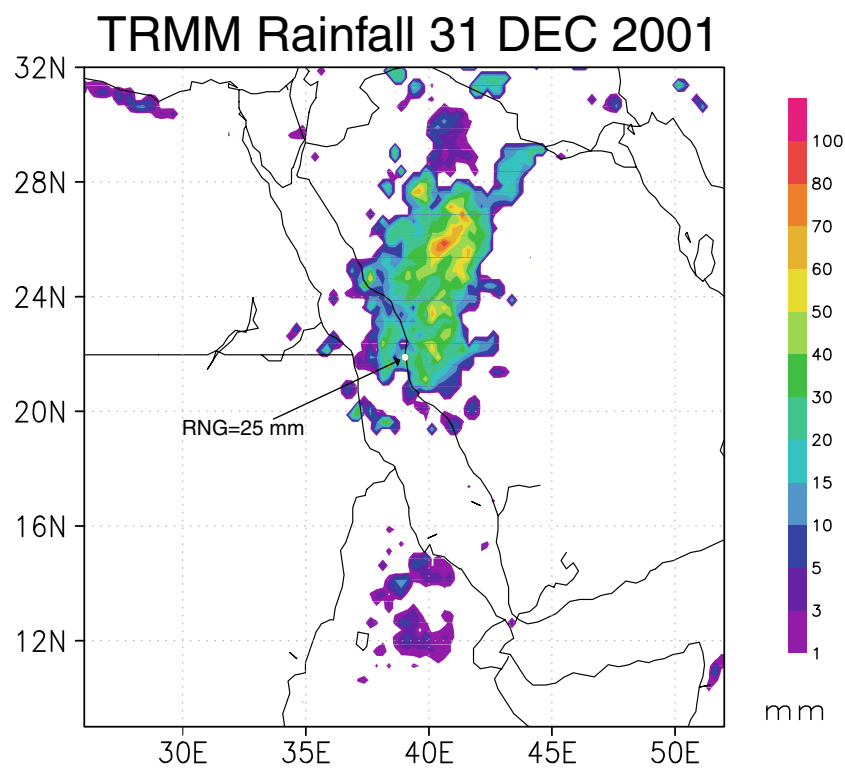

Fig. 8 Same as Fig. 5 but for 31 December 2001 


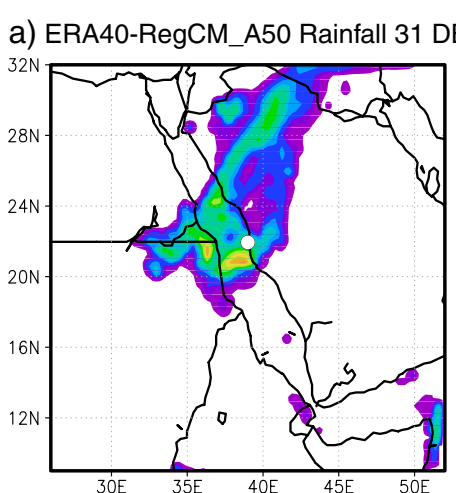

d) NNRP2-RegCM_A50 Rainfall 31 DEC 2001

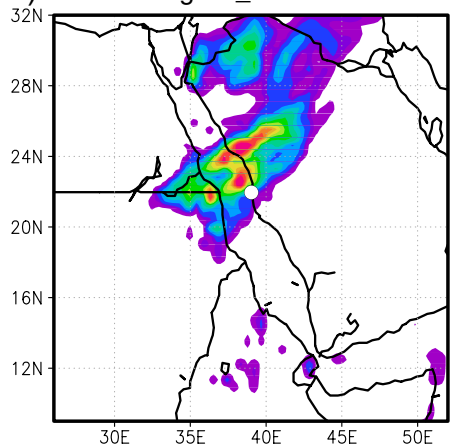

b) ERA40-RegCM_B50 Rainfall 31 DEC 2001

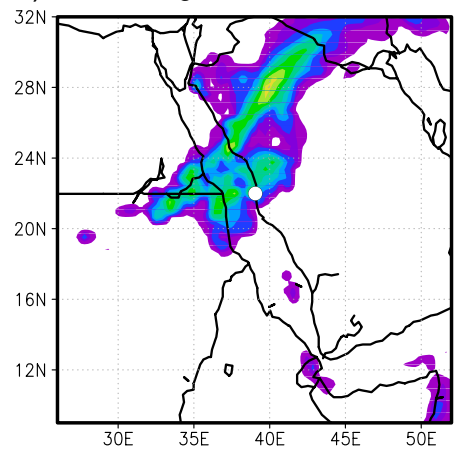

e) NNRP2-RegCM_B50 Rainfall 31 DEC 2001

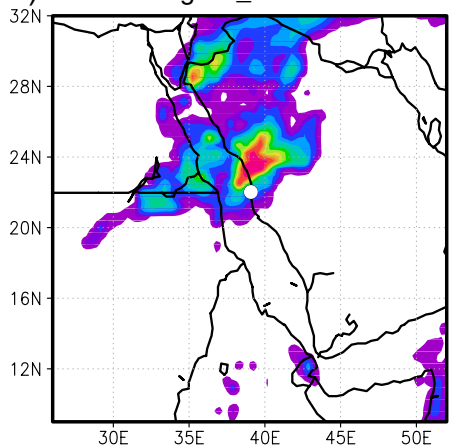

c) ERA40-RegCM_C50 Rainfall 31 DEC 2001

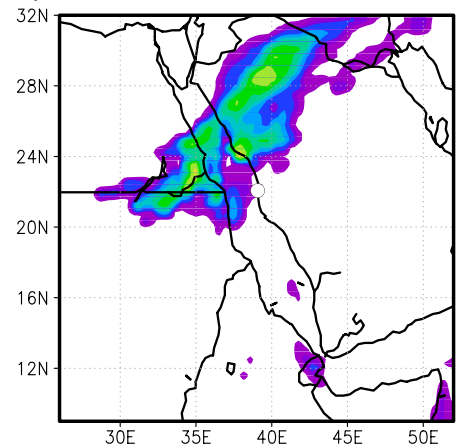

f) NNRP2-RegCM_C50 Rainfall 31 DEC 2001

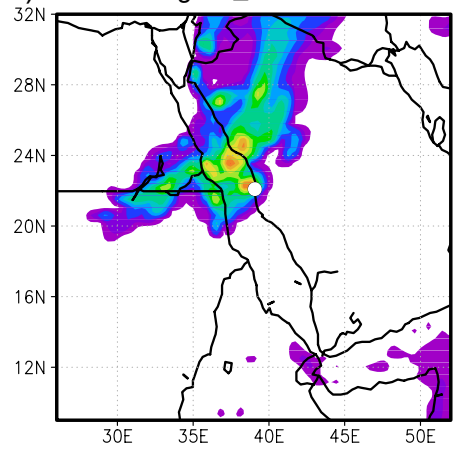

$\mathrm{mm}$

Fig. 9 Same as Fig. 6 but for 31 December 2001

(towards the north) band crossing the northern part of the Arabian Peninsula with the maxima concentrated at the center. It also indicates about $30 \mathrm{~mm}$ of rainfall intensity around Jeddah. The simulation of this rainfall event using different model domains and boundary forcings is also now discussed.

The distribution of simulated rainfall (millimeter) on 31 December 2001 is displayed in Fig. 9 for ERA40 (top panels) and NNRP2 (bottom panels) for domain A (left panels), domain B (middle panels), and domain C (right panels). All the simulations display a spatial distribution of rainfall in an inclined band oriented north-south. Only EAR40-RegCM_B50 captures a reasonable maximum rainfall at the center of the rainband closer to the TRMM. However, the rainband is thicker in the cases of NNRP2 as RegCM3 extends it to the northwest of the Arabian Peninsula and overestimates rainfall intensity in those regions. Over the Red Sea coastline, NNRP2-RegCM represents the maxima of the rainfall fairly well in the three domains compared to the TRMM observations but shifts them further north.

In the same vein as the previous case, to quantify the rainfall amount simulated by the RegCM3 for all the three domains using the two boundary forcings, rainfall was extracted near the Jeddah station (Fig. 10). The rain gauge and TRMM observations give almost the same amount of peak rainfall for 31 December 2001 (Fig. 10). Out of all the cases, only ERA40-RegCM_A50 and NNRP2-RegCM_B50 were able to find rainfall peaks close to the TRMM and the rain gauge data on the same day.

In general, for the first cases, ERA40-RegCM_A50 and NNRP2-RegCM_B50 display a better spatial distribution, while ERA40-RegCM_A50, ERA40-RegCM_B50, NNRP2RegCM_A50, and NNRP2-RegCM_B50 show a closer amount

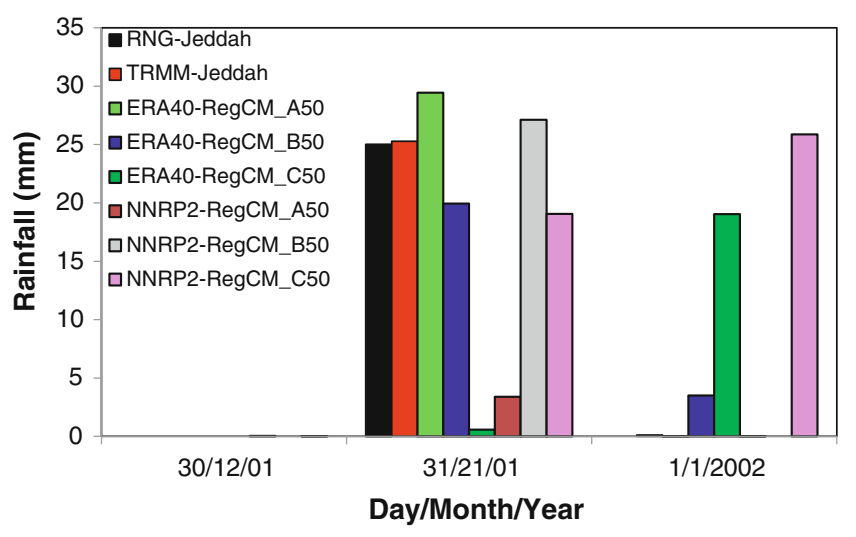

Fig. 10 Same as Fig. 7 but for the period during 30 December 2001 to 1 January 2002 
Fig. 11 The relative humidity (in percent) and superimposed wind vectors (meters per second) at $925 \mathrm{hPa}$ for, respectively, ERA40 and NNRP2 (upper panels; a, b), ERA40-

RegCM_A50 and NNRP2-

RegCM_A50 (middle panels; c, d), and ERA40-RegCM B50 and NNRP2-RegCM_B50 (lower panels; e, f) for $\mathbf{8}$ January 1999

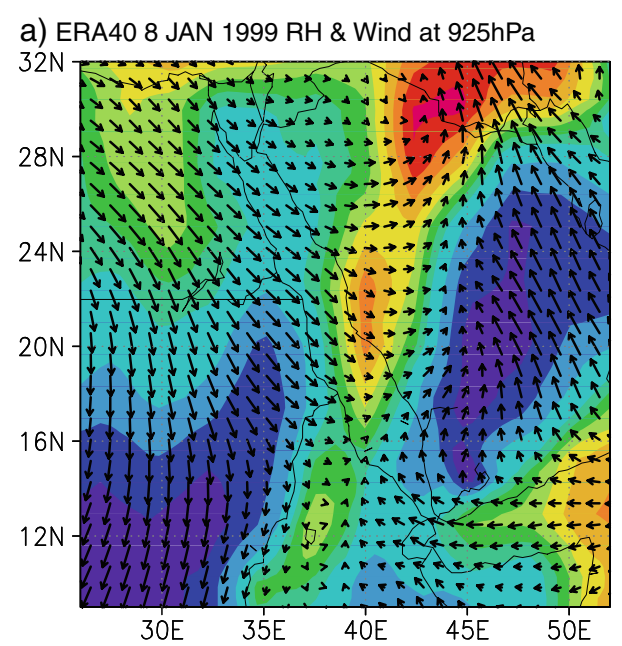

c) ERA40-RegCM_A50 8 JAN $1999 \mathrm{RH} \&$ Wind at 925hPa

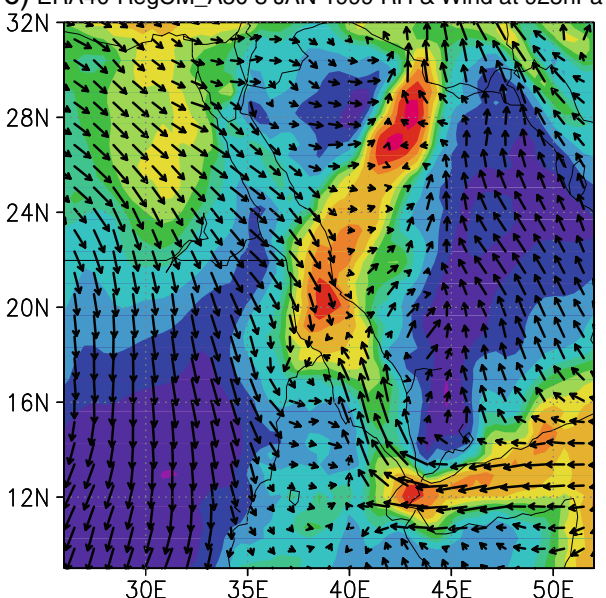

e) ERA40-RegCM_B50 8 JAN $1999 \mathrm{RH} \&$ Wind at 925hPa

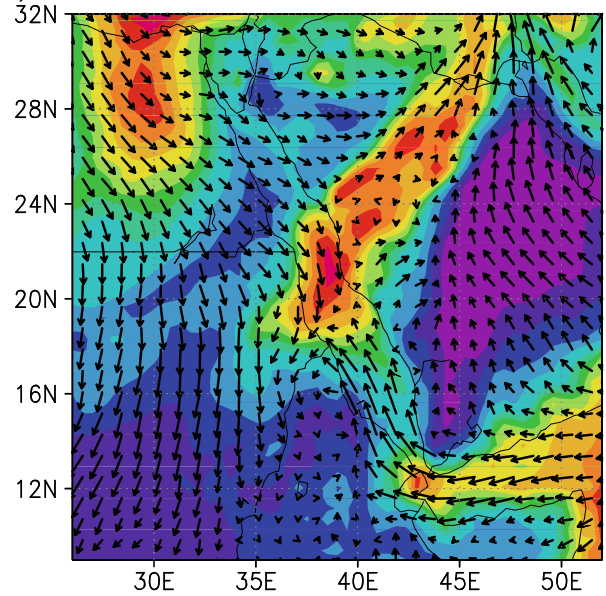

b) NNRP2 8 JAN $1999 \mathrm{RH} \&$ Wind at $925 \mathrm{hPa}$

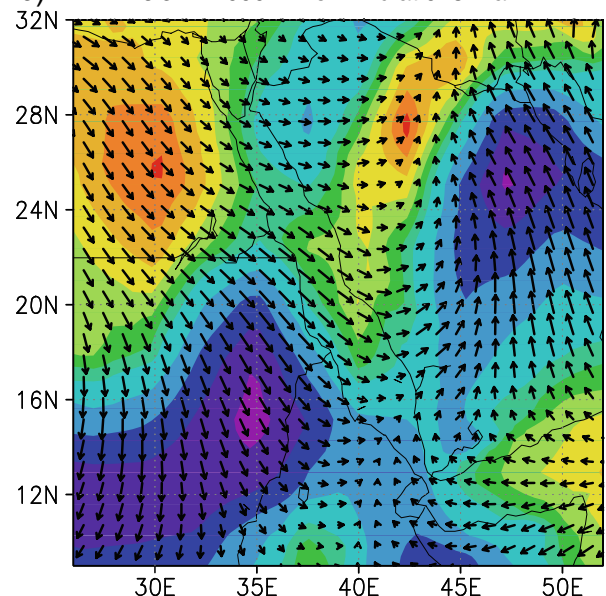

d) NNRP2-RegCM_A50 8 JAN $1999 \mathrm{RH} \&$ Wind at 925hPa

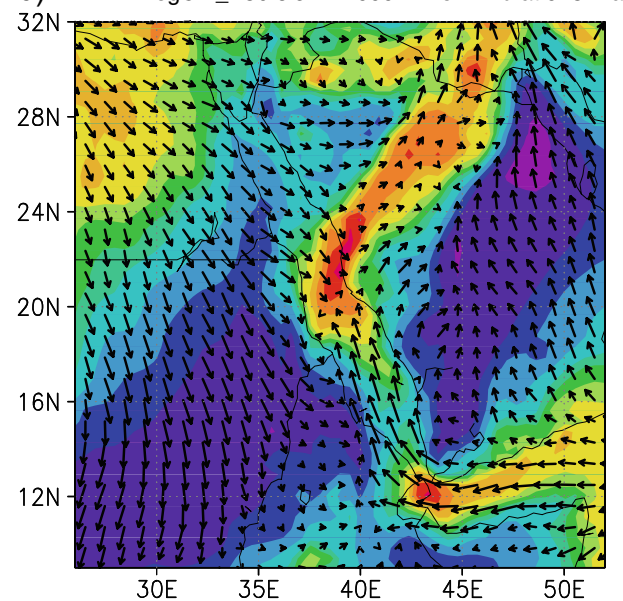

f) NNRP2-RegCM_B50 8 JAN $1999 \mathrm{RH} \&$ Wind at 925hPa 32N Dyy $28 \mathrm{~N}$

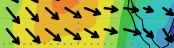

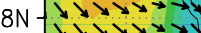
$\rightarrow \rightarrow \rightarrow \rightarrow$

,

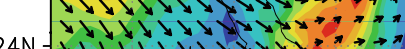

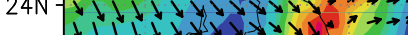

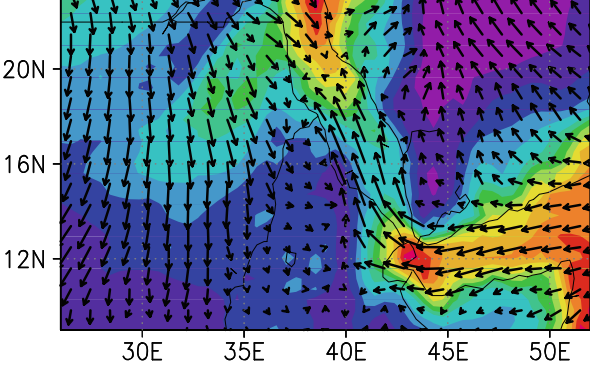

$\%$ of rainfall when compared to the TRMM and the Jeddah rain gauge datasets. For the second case studied, EAR40RegCM B50, NNRP2-RegCM A50, NNRP2-RegCM B50, and NNRP2-RegCM_C50 provided encouraging results in reproducing better spatial distributions of rainfall when compared to the TRMM data. Note that switching B to C can cause differences in the simulations, but these can be ascribed to model internal variability (Giorgi and Bi 2000), and in this 
regard, analysis in the next section will be focused mainly on inter-comparison simulations performed over domains $\mathrm{A}$ and $\mathrm{B}$ (with the better performing reanalysis forcings).

When the rainfall is extracted near the Jeddah station, only ERA40-RegCM_A50, ERA40-RegCM_B50, and NNRP2RegCM_B50 capture reasonable rainfall peaks close to both TRMM and the Jeddah rain gauge amounts. This indicates that different combinations of domain sizes and boundary forcings provide different performances for the regional climate model RegCM3 in simulating these rainfall events. In addition, they suggest that the simulation of high intensity rainfall events over the studied region is more sensitive to domain size than boundary forcing. Furthermore, ERA40RegCM_A50 and NNRP2-RegCM_B50 provide the best
Fig. 12 The same as in Fig. 11 but for 31 December 2001

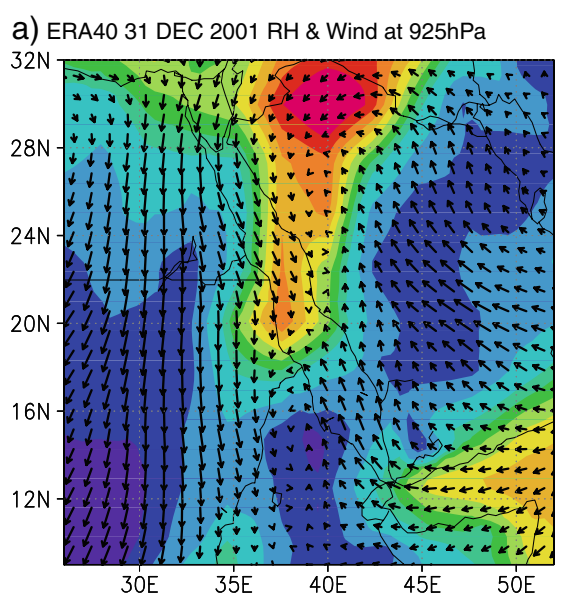

C) ERA40-RegCM_A50 31 DEC $2001 \mathrm{RH} \&$ Wind at 925hPa

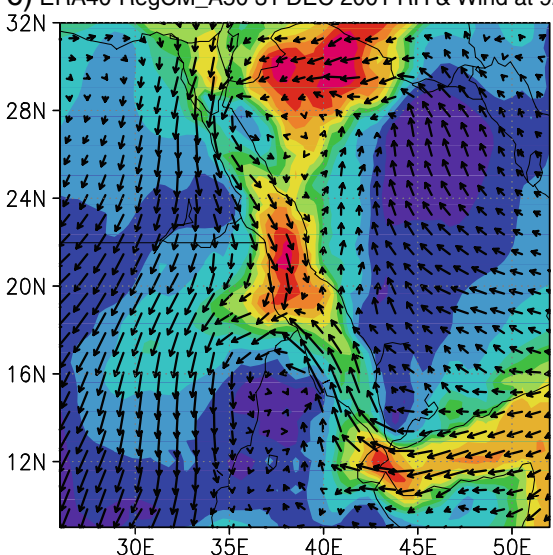

e) ERA40-RegCM B50 31 DEC $2001 \mathrm{RH} \&$ Wind at 925hPa

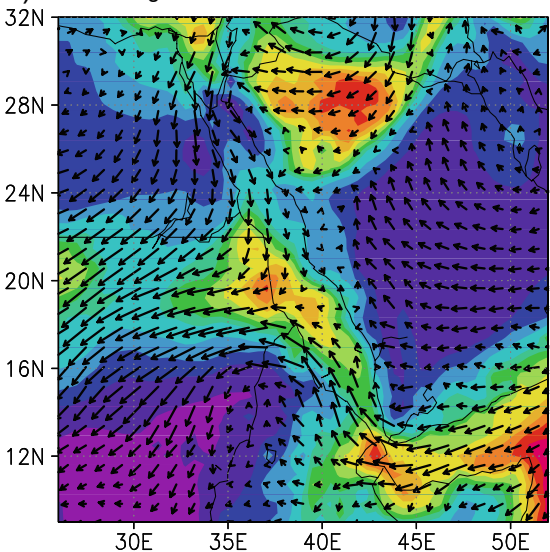

b) NNRP2 31 DEC $2001 \mathrm{RH} \&$ Wind at $925 \mathrm{hPa}$

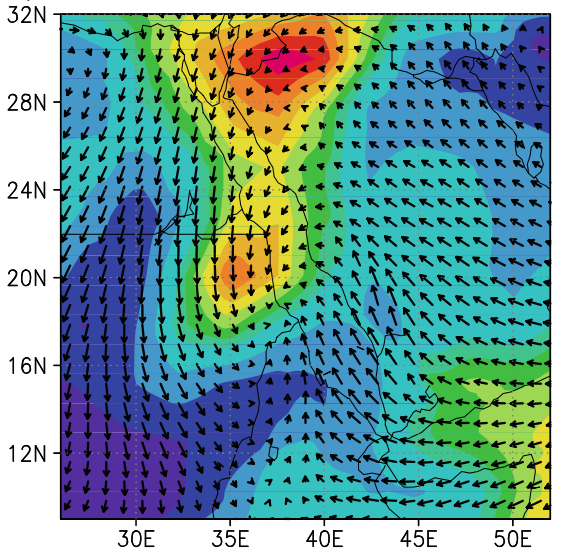

d) NNRP2-RegCM_A50 31 DEC $2001 \mathrm{RH} \&$ Wind at 925hPa

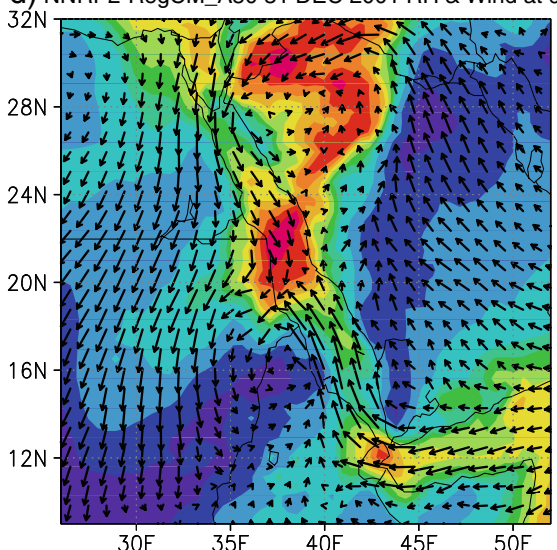

f) NNRP2-RegCM_B50 31 DEC 2001 RH \& Wind at 925hPa

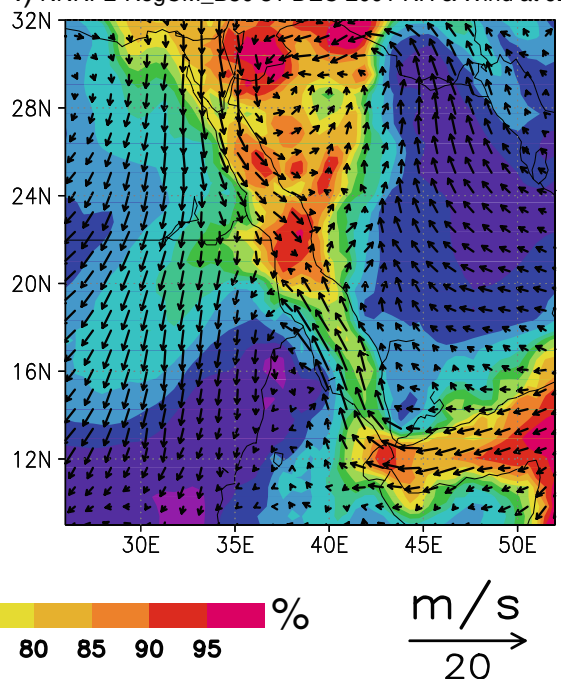


performances (although NNRP2-RegCM_A50 is by no means poor) in indicating the role of the center of the domain. The better representation of these events using a smaller (relatively bigger) domain in the case of ERA40 (NNRP2) indicates that the stronger (weaker compared to ERA40) influence and constraint of lateral boundary forcings are critical in capturing these features.

\subsection{Synoptic features during the cases}

To investigate the above issues, relative humidity and superimposed wind vectors at $925 \mathrm{hPa}$ are plotted in Fig. 11 for ERA40 and NNRP2 (upper panels), respectively, ERA40-RegCM_A50 and NNRP2-RegCM_A50 (middle panels), and ERA40-RegCM_B50 and NNRP2RegCM_B50 (lower panels) are considered for the first event. Reanalyses (ERA40 and NNRP2 for Fig. 11a and b, respectively) show that the wind vectors are mainly northwesterly in the western part of the domain and southeasterly in the eastern part. After crossing the Red Sea, wind vectors deflect towards the north and become southwesterlies, creating a convergence zone (together with the south-easterlies from the Indian Ocean) in an inclined band over the northern part of the Arabian Peninsula. As a result, relative humidity reaches a maximum in that region, probably because of high moisture convergence. Maxima of relative humidity, located in that band in the north and along the Red Sea coastline (near Jeddah), and coinciding with the area of heavy rainfall, are higher in ERA40 than in NNRP2. When driven by ERA40 in domain A (Fig. 11c), RegCM3 adequately captures the area of higher and lower relative humidity but shifts the maxima to over the Red Sea. It also tends to underestimate the wind vector almost everywhere in the domain. When RegCM3 is driven by NNRP2 over domain A (Fig. 11d), simulation captures the maxima in the inclined band shown in ERA40 and NNRP2 but relative humidity appears to be overestimated along the Red Sea coastline. Wind field in this case is generally stronger for NNRP2-RegCM_A50 than ERA40RegCM_A50, and the south-easterlies are overestimated in the southern part of the Red Sea and in the Indian Ocean. The existence of wind convergence is prominent over the Red Sea where relative humidity is overestimated compared to both ERA40 and NNRP2. In domain B, both simulations (ERA40-RegCM_B50 and NNRP2-RegCM_B50 in Fig. 11e and f, respectively) show similar wind vectors and moisture distribution but the tilted band of high relative humidity is wider in ERA40-RegCM_B50.

The same analysis has been undertaken for the second case studied. Both ERA40 and NNRP2 (Fig. 12a, b) show similar wind vector distributions, which are almost northerlies in Africa and south-easterlies in the Arabian Peninsula. A vertical band of maxima of relative humidity

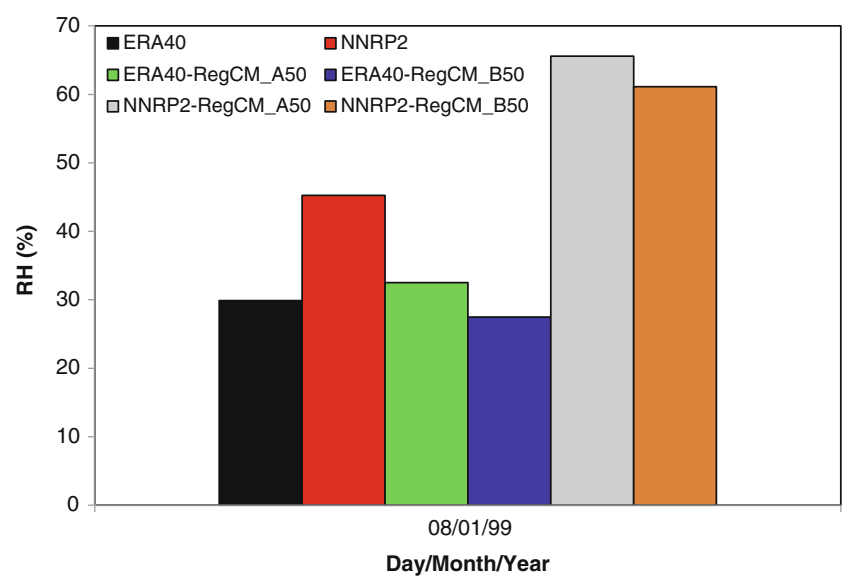

Fig. 13 Bar graph of the relative humidity (in percent) extracted near Jeddah station for, respectively, ERA40, NNRP2, ERA40RegCM_A50, ERA40-RegCM_B50, NNRP2-RegCM_A50, and NNRP2-RegCM_B50 for 8 January 1999

coinciding with the area of heavy rainfall is shown in both spatial distributions. However, ERA40 displays the second band of maxima over the Red Sea, whereas NNRP2 extends it over Africa. Over domain A, ERA40RegCM_A50 (Fig. 12c) and NNRP2-RegCM_A50 (Fig. 12d) provide similar wind vectors and vertical bands of higher relative humidity; they are very close to each other and to both reanalyses, with the southern maxima over the Red Sea near Jeddah. In domain B, ERA40RegCM_B50 (Fig. 12e) does not show the vertical band of higher moisture, instead it displays two maxima over the north of the peninsula and over the Red Sea, interrupted by low values of relative humidity. Wind direction over Africa is dissimilar to the reanalyses. In this domain, NNRP2RegCM_B50 (Fig. 12f) provides the best performance by showing the vertical band of high relative humidity and capturing the maxima in the northern part of the peninsula and along the Red Sea coastline around Jeddah. The wind vectors (strengths and directions) are overall closer to both

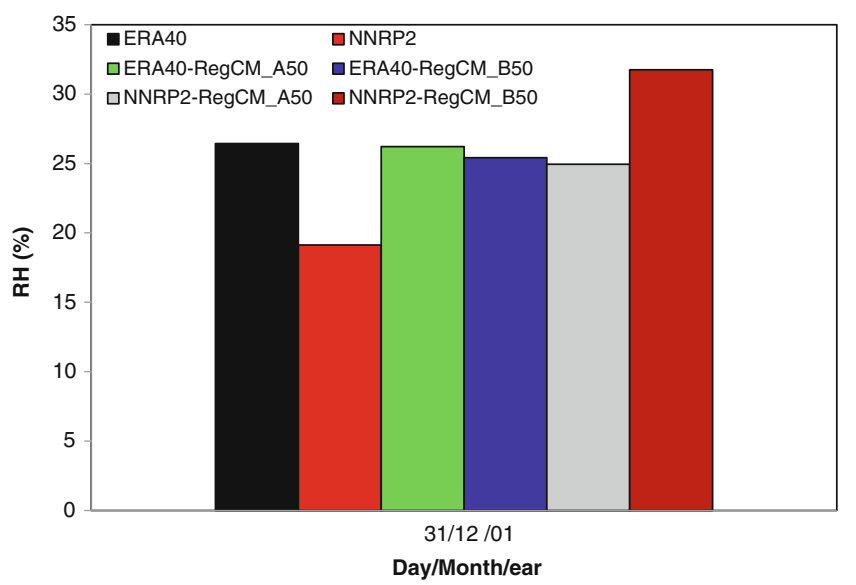

Fig. 14 Same as Fig. 13 but for 31 December 2001 
reanalyses in this case. Those over the Red Sea, near Jeddah, and easterlies from the Indian Ocean are stronger in NNRP2-RegCM_B50 than in ERA40-RegCM_A50.

As before with regard to precipitation, relative humidity values are extracted near the Jeddah station for ERA40, NNRP2, ERA40-RegCM_A50, ERA40-RegCM_B50, NNRP2-RegCM_A50, and NNRP2-RegCM_B50 and are displayed in Fig. 13, concerning the first case study. The ERA40-RegCM_A50 values lie between those of ERA40 and NNRP2, while NNRP2-RegCM_A50 overestimates both of them. For domain B, ERA40-RegCM_B50 underestimates both reanalyses values, while NNRP2-RegCM_B50 still overestimates them with a lower value compared to those of domain A. Note that the stronger value of relative humidity provided by NNRP2-RegCM in both domains for this case might have led to the simulation of a higher amount of rainfall over Jeddah, as shown in the previous section. A similar plot is displayed in Fig. 14 with regard to the second case study. ERA40-RegCM_A50 and EAR40-RegCM_B50 lie between the ERA40 and NNRP2 values but relative humidity is lower in domain B, while NNRP2-RegCM_B50 tends to overestimate it over Jeddah when domain B is used.
In general, when RegCM3 is driven by ERA40, simulation provides lower values for relative humidity for the larger domain (domain B) than when the smaller domain is used. In the case of NNRP2 boundary forcing, relative humidity is overestimated; it is higher than the values provided by RegCM3 driven by ERA40 most of the time. In combination with the results found above, it is revealed that $\mathrm{RegCM} 3$ driven by ERA40 is relatively better in simulating wind vectors and relative humidity in and around Jeddah when the smaller domain is used. In contrast, using NNRP2 as boundary forcing, RegCM3 performs better in the larger domain (domain $\mathrm{B}$ ). This may explain why the stronger influence of large-scale features in ERA40 and their relatively weaker influence in NNRP2 (than in the case of ERA40) lead to a better simulation of high intensity rainfall events in and around Jeddah.

\subsection{Sensitivity to resolution}

As we are concerned with the amount of rainfall in Jeddah, utilizing a very high resolution may play an important role in improving the simulations of high intensity rainfall events in this region. Accordingly, high-resolution simu-
Fig. 15 Simulations for ERA40-RegCM_A50 (top left, a), ERA40-RegCM_A25 (top right, b), NNRP2-RegCM_A50 (bottom left, c), and NNRP2RegCM_A25 (bottom right, d) for 8 January 1999. The location of Jeddah is shown by the white dot

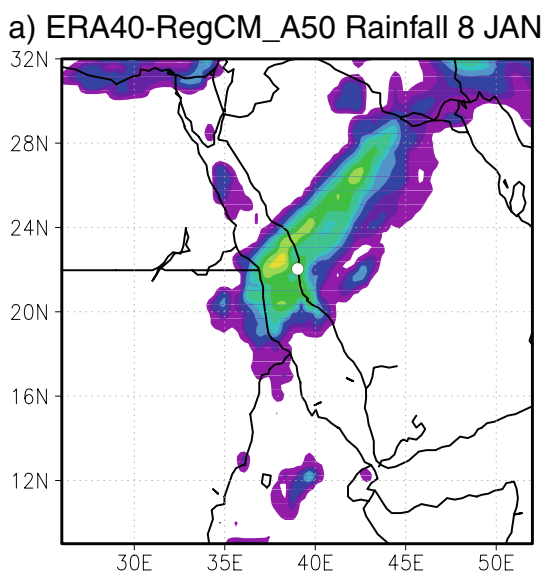

c) NNRP2-RegCM_A50 Rainfall 8 JAN 1999

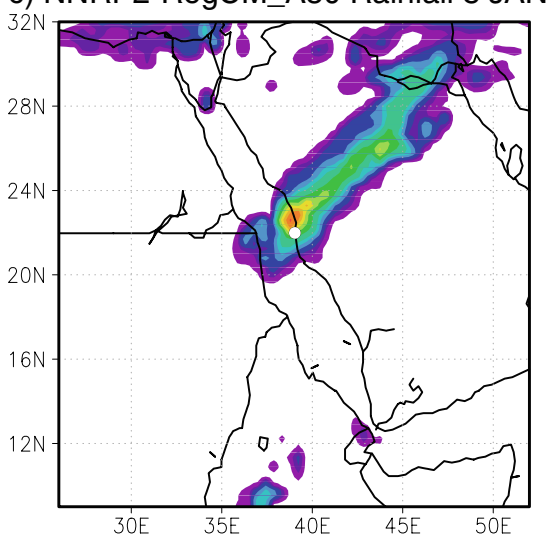

b) ERA40-RegCM_A25 Rainfall 8 JAN 1999

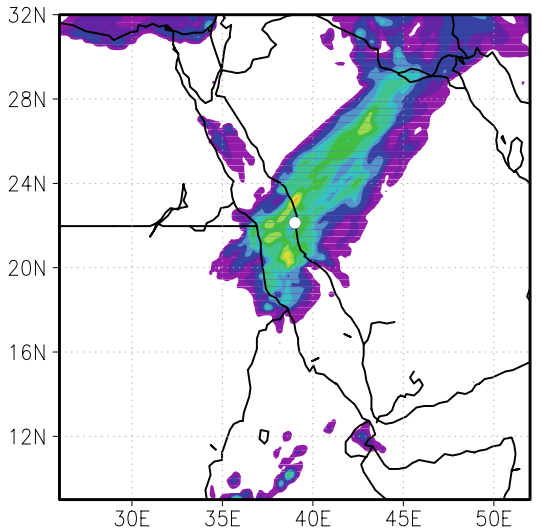

d) NNRP2-RegCM_A25 Rainfall 8 JAN 1999

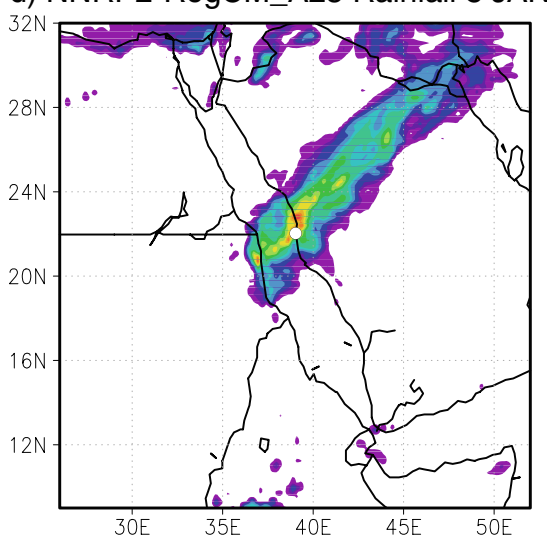

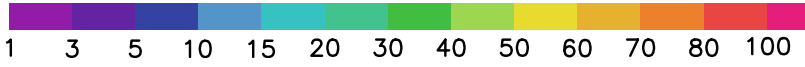

$\mathrm{mm}$ 
lations were conducted at $25 \mathrm{~km}$ over domain $\mathrm{A}$, where RegCM3 using ERA40 boundary forcings performed better and NNRP2 showed relatively low accuracy. These were compared with the previous ones done with $50 \mathrm{~km}$ in the same domain. Simulations for the first case are shown in Fig. 15a-d for, respectively, ERA40-RegCM_A50, ERA40RegCM_A25, NNRP2-RegCM_A50, and NNRP2RegCM_A25. A similar plot is used for the second case study, and the results are displayed in Fig. 16. Both figures show that the high-resolution simulations have similar patterns than those of the corresponding runs at $50 \mathrm{~km}$, with more fine-scale features in the rainband. Almost all of them locate the rainfall maxima in the areas found in the $50 \mathrm{~km}$ corresponding runs, except NNRP2-RegCM_A25 for the second case study. In this simulation, the rainfall maxima found in the low-resolution run are split into several areas, spread widely along the coastline of the Red Sea, and extended south around Jeddah in the high resolution.

For the first case study, if rainfall is extracted near the Jeddah station for all the four cases displayed in Fig. 15a-d and compared to TRMM and Jeddah rain gauge, the results reveal that the high resolution does not have any effect when NNRP2 is used as boundary forcing, while in the case of ERA40, rainfall intensity is overestimated when compared to both TRMM and the Jeddah rain gauge (Fig. 17). In the second case study, the high resolution tends to decrease the amount of rainfall overestimated in the case of ERA40 (Fig. 18). In this case study, when NNRP2 is used as boundary forcing, the high resolution improves remarkably the simulations of rainfall amount over Jeddah. In fact, from $2.5 \mathrm{~mm}$, it increases up to $20 \mathrm{~mm}$, closer to the observations of TRMM and the Jeddah rain gauge $(\sim 25 \mathrm{~mm})$. This is connected to the fact that rainfall maxima in this case are more extended south, next to Jeddah as explained above.

In general, using high resolution does not guarantee better simulation of high rainfall intensity events in Jeddah. However, the fine-scale features (small maxima of rainfall) could help to set up more accurate amounts of rainfall depending on the proximity of the grid points to the region of interest.
Fig. 16 The same as in Fig. 15 but for 31 December 2001 a) ERA40-RegCM_A50 Rainfall 31 DEC 2001

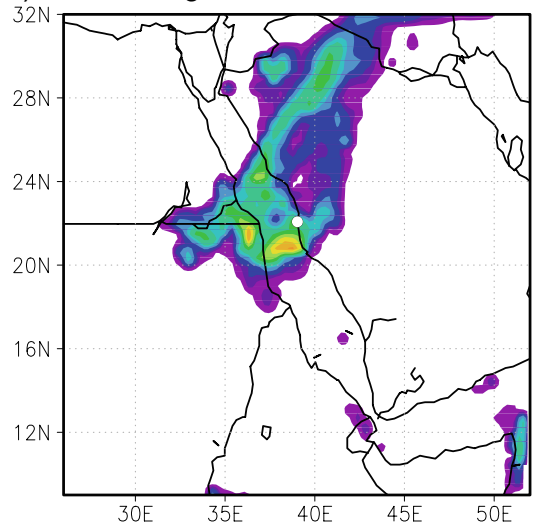

c) NNRP2-RegCM_A50 Rainfall 31 DEC 2001

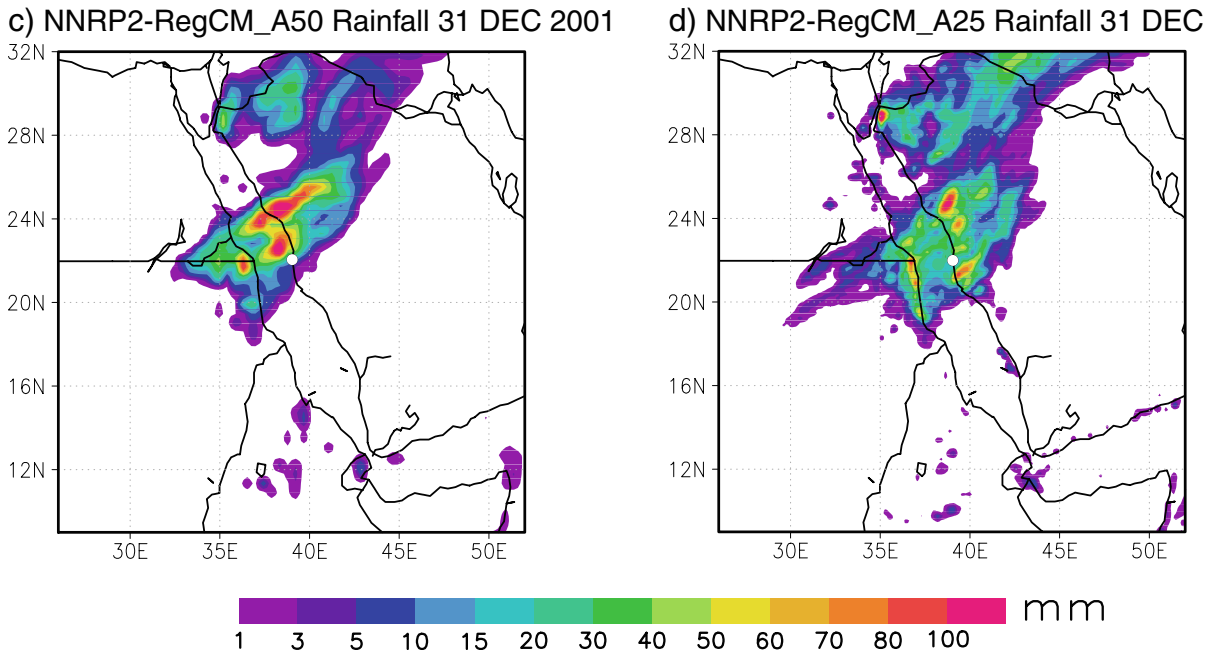

b) ERA40-RegCM_A25 Rainfall 31 DEC 2001

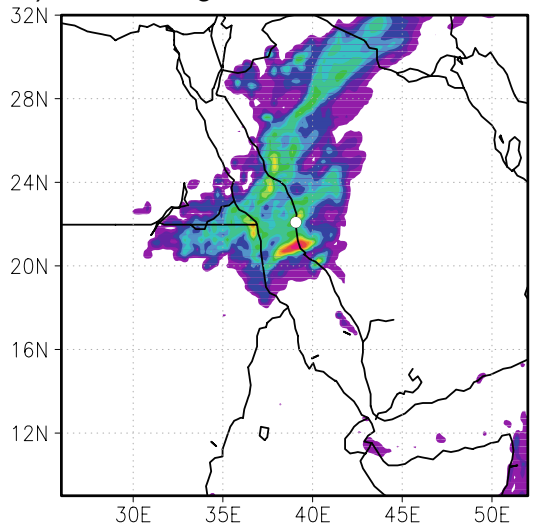

d) NNRP2-RegCM_A25 Rainfall 31 DEC 2001 


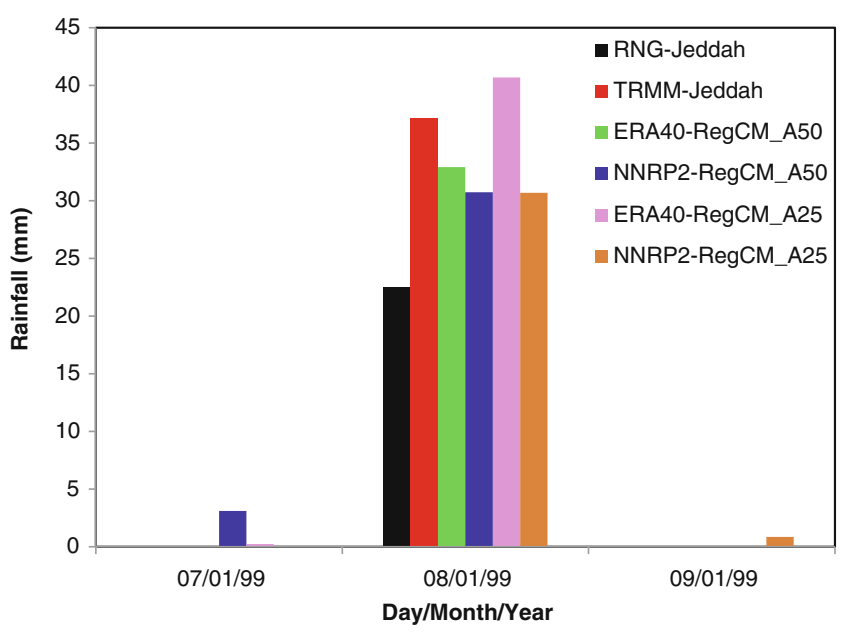

Fig. 17 Bar graph plot of the daily rainfall (millimeter) during 7-9 January 1999 recorded by the rain gauge $(R N G)$ at Jeddah, observed by TRMM, and simulated by ERA40-RegCM_A50, ERA40RegCM_A25, NNRP2-RegCM_A50, and NNRP2-RegCM_A25 extracted near the Jeddah station

\section{Discussion and conclusion}

In this paper, the sensitivity of the regional climate model (RegCM3) in simulating heavy rainfall events over the Jeddah region of Saudi Arabia using different domain sizes and lateral boundary forcings is reported. Domain choice, and therefore the location of the lateral boundaries, is of critical importance in the issue of regional climate modeling over the Arabian Peninsula, where data are sparse and large-scale synoptic features have a strong influence on the regional climate. In addition, as simulated precipitation results from a sum of physical processes, involving water vapor advection from lateral boundaries and moisture sources from the surface, the driving large-scale fields may play an important role.

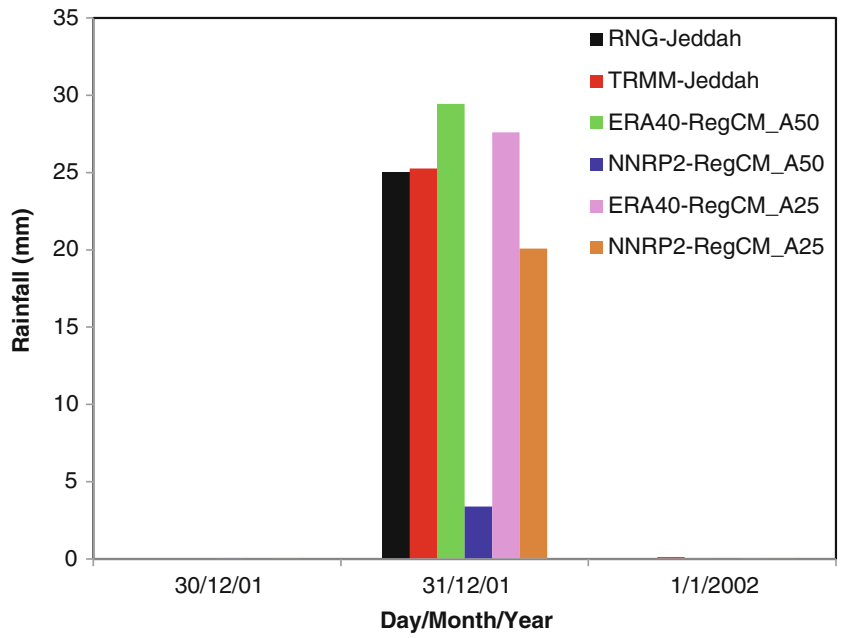

Fig. 18 Same as Fig. 17 but for the period during 30 December 2001 to 1 January 2002
Before conducting the sensitivity study for the model to simulate extreme rainfall events, the regional model's performance was assessed for the 12-year climatology. RegCM3 performed well in simulating the annual and the seasonal mean climatology of precipitation over the Arabian Peninsula as well as the contrast between the wet and dry years (in terms of the amount and locations of the rainbands). It has also been shown that the observed rainfall amounts are very low and that the sensitivity study vis-à-vis simulated precipitation may be better achieved using targeted specific cases of intense rainfall events. Notwithstanding this proviso, the results indicate that different combinations of domain sizes and boundary forcings provide different skills for RegCM3 in simulating heavy rainfall events around Jeddah and that ERA40RegCM_A50 and NNRP2-RegCM_B50 show the best performances although NNPRP2-RegCM_A50 is quite encouraging. These indicate that RegCM3 captures adequately the simulation of intense rainfall events better both in the small domain when ERA40 is used at the boundaries and in the larger domain when NNRP2 is forcing the regional model. It is noted that these domains have the same center. The performance of RegCM3 is poor if the larger domain is used, with the center shifted towards the east in both forcings and case studies. This attests to the important role of the domain center and therefore the locations of lateral boundaries in capturing the heavy rainfall events in and around Jeddah, Saudi Arabia.

To address the issue of the role of large-scale fields in the performance of RegCM3 in simulating these events using ERA40 in the small domain and NNRP2 in the larger domain, $925 \mathrm{hPa}$ relative humidity and superimposed wind vectors for each event were considered. The results reveal that RegCM3 driven by ERA40 simulates higher values of relative humidity and stronger wind vectors around Jeddah within the smaller domain (rather than the larger domain), thus providing its best performance. However, when NNRP2 reanalyses are placed at the boundaries, RegCM3 reproduces those large-scale features in the larger domain better and especially in Jeddah and the surrounding regions. This corroborates the stronger (relatively weaker) influence of lateral boundary forcings on the regional climate model needed to capture such events when ERA40 (NNRP2) is used.

Finally, to highlight the relative role of resolution in the simulations of these high intensity rainfall events around Jeddah, high-resolution simulations were performed over domain A with RegCM3 forced by ERA40 and NNRP2, respectively. Note that the regional climate model had better performance in domain A in the case of ERA40 than NNRP2. It was shown that the high resolution remarkably improves the simulation of the amount of rainfall around Jeddah and the surroundings by splitting the maxima 
around the Red Sea coastlines and extending them further south. Although other cases show differences in the amounts of rainfall simulated in Jeddah, they do not show any consistent improvements. Therefore, high resolution does not always guarantee increased performance for the regional climate model in simulating high intensity rainfall events, except if the fine-scale features that showed split rainfall maxima, are shifted towards the region of interest.

Acknowledgments The author would like to acknowledge the Presidency of Meteorology and Environment (PME) of Saudi Arabia for providing the rain gauge data. The RegCM3 group of ICTP, Trieste, Italy is acknowledged for providing the model with LBCs. TRMM data were acquired from their website at http://trmm.gsfc.nasa.gov.

\section{References}

Abdullah MA, Al-Mazroui M (1998) Climatological study of the southwestern region of Saudi Arabia. I. Rainfall analysis. Clim Res 9:213-223

Almazroui M (2010) Calibration of TRMM rainfall climatology over Saudi Arabia during 1998-2009. Atmos Res. doi:10.1016/j. atmosres.2010.11.006

Al-Mazroui M (1998) Climatological study over the southwestern region of the Kingdom of Saudi Arabia with special reference to rainfall distribution, Master thesis, Department of Meteorology, Faculty of Meteorology, Environment and Arid Land Agriculture, King Abdulaziz University, Jeddah, Saudi Arabia

Atlas (1984) Water atlas of Saudi Arabia. Water resource department. Ministry of Agriculture and Water, Riyadh

Camara M, Jenkins G, Konare A (2010) Impacts of dust on West African climate during 2005 and 2006. Atmos Chem Phys Discuss 10:3053-3086. doi:10.5194/acpd-10-3053-2010

Dickinson RE, Henderson-Sellers A, Kennedy PJ (1993) Biosphereatmosphere transfer scheme (BATS) version 1e as coupled to the NCAR community climate model. NCAR Tech. Note NCAR/ TN-387 +STR, p 72

Diffenbaugh NS, Pal JS, Trapp RJ, Giorgi F (2005) Fine-scale processes regulate the response of extreme events to global climate change. Proc Natl Acad Sci 102:15774-15778

Fritsch JM, Chappell CF (1980) Numerical prediction of convectively driven mesoscale pressure systems. Part I: convective parameterization. J Atmos Sci 37:1722-1733

Giorgi F, Bi X (2000) A study of internal variability of a regional climate model. J Geophys Res 105:29503-29521

Giorgi F, Mearns LO (1999) Introduction to special section: regional climate modeling revisited. J Geophys Res 104:6335-6352

Giorgi F, Marinucci MR, Bates GT (1993a) Development of a second generation regional climate model (REGCM2). Part I: boundary layer and radiative transfer processes. Mon Weather Rev 121:2794-2813

Giorgi F, Marinucci MR, Bates GT, DeCanio G (1993b) Development of a second generation regional climate model (REGCM2). Part II: convective processes and assimilation of lateral boundary conditions. Mon Weather Rev 121:2814-2832

Giorgi F, Hostetler SW, Shields BC (1994) Analysis of the surface hydrology in a regional climate model. Q J R Meteorol Soc 120:161-184

Giorgi F, Bi X, Pal JS (2004) Mean, interannual variability and trends in a regional climate change experiment over Europe. Part II: future climate scenarios (2071-2100). Climate Dyn 23:839-858

Grell GA (1993) Prognostic evaluation of assumptions used by cumulus parameterizations. Mon Weather Rev 121:764-787
Grell GA, Dudhia J, Stauffer DR (1994) Description of the fifth generation Penn State/NCAR Mesoscale Model (MM5). Tech Rep TN-398+STR. NCAR, Boulder, p 121

Holtslag AAM, de Bruijn EIF, Pan H-L (1990) A high resolution air mass transformation model for short-range weather forecasting. Mon Weather Rev 118:1561-1575

Jones RG, Murphy JM, Noguer M (1995) Simulation of climate change over Europe using a nested regional-climate model. Part I: assessment of control climate, including sensitivity to location of boundaries. Q J R Meteorol Soc 121:1413-1450. doi:10.1002/ qj. 49712152610

Kalnay E, Kanamitsu M, Kistler R, Collins W, Deaven D, Gandin L, Iredell M, Saha S, White G, Wollen J, Zhu Y, Chelliah M, Higgins W, Ebisuzaki W, Janowiak J, Mo KC, Ropelewski C, Wang J, Leetmaa A, Reynolds R, Jenne R, Joseph D (1996) The NCEP/NCAR 40-year reanalysis project. Bull Am Meteorol Soc 77:437-471

Kiehl JT, Hack JJ, Bonan GB, Boville BA, Breigleb BP, Williamson DL, Rasch PJ (1996) Description of the NCAR community climate model (CCM3), NCAR Tech Note NCAR/TN-4201STR, p 152

Kistler R, Kalnay E, Collins W, Saha S, White G, Wollen J, Chelliah M, Ebisuzaki W, Kanamitzu M, Kousky V, van den Dool H, Jenne R, Fiorino M (2001) The NCEP NCAR 50-year reanalysis: monthly means CD-ROM and documentation. Bull Am Meteorol Soc 2:247-267

Köppen W (1936) Das Geographisca system der Klimate. Handbuch der Klimatologie. Köppen W, Geiger G (eds) 1(C) Gebr. Borntraeger pp 1-44

Leung LR, Ghan SJ, Zhao Z-C, Luo Y, Wang W-C, Wei H-L (1999) Intercomparison of regional climate simulations of the 1991 summer monsoon in eastern Asia. J Geophys Res 104(D6):64256454. doi:10.1029/1998JD200016

Litta J, Chakrapani B, Mohankumar K (2007) Mesoscale simulation of an extreme rainfall event over Mumbai, India, using a highresolution MM5 model. Meteorol Appl 14:291-295

Nobre P, Antonio DM, Sun L (2001) Dynamical downscaling of seasonal climate prediction over Nordeste Brazil with ECHAM3 and NCEP's regional spectral models at IRI. Bull Am Meteorol Soc 82:2787-2796

Pal JS, Small EE, Eltahir E (2000) Simulation of regional-scale water and energy budgets: representation of subgrid cloud and precipitation processes within RegCM. J Geophys Res 105 (D24):29,579-29,594. doi:10.1029/2000JD90041

Pal JS, Giorgi F, Bi X, Elguindi N, Solmon F, Rauscher SA, Francisco R, Zakey A, Winter J, Ashfaq M, Syed F, Bell JL, Diffenbaugh NS, Karmacharya J, Konaré A, Martinez D, Da Rocha RP, Sloan LC, Steiner AL (2007) Regional climate modeling for the developing world: the ICTP RegCM3 and RegCNET. Bull Am Meteorol Soc 88:1395-1409

Rauscher SA, Seth A, Qian J-H, Camargo SJ (2006) Domain choice in an experimental nested modeling prediction system for South America. Theor Appl Climatol 86:229-246. doi:10.1007/s00704006-0206-Z

Reynolds RW, Smith TM (1994) A high-resolution global sea surface temperature climatology. J Climate 8:1571-1583

Reynolds RW, Rayner NA, Smith TM, Stokes DC, Wang W (2002) An improved in situ and satellite SST analysis. J Climate 15:1609-1625

Reynolds RW, Smith TM, Liu C, Chelton DB, Casey KS, Schlax MG (2007) Daily high-resolution blended analyses for sea surface temperature. J Climate 20:5473-5496

Santese M, Perrone MR, Zakey AS, FDe T, Giorgi F (2010) Modeling of Saharan dust outbreaks by RegCM3: case studies. Atmos Chem Phys 10:133-156

Seth A, Giorgi F (1998) The effect of domain choice on summer precipitation simulation and sensitivity in a regional climate model. J Climate 11:2698-2712 
Seth A, Rauscher SA, Camargo SJ, Qian JH, Pal JS (2007) RegCM3 regional climatologies for South America using reanalysis and ECHAM global model driving fields. Climate Dyn 28:461-480. doi:10.1007/s00382-006-0191-z

Shiao CH, Juang HMH (2006) Sensitivity study of the climate simulation over East Asia with the CWB regional spectral model. Terr Atmos Ocean Sci 17:593-612

Sylla MB, Gaye AT, Pal JS, Jenkins GS, Bi X (2009) High resolution simulations of West African climate using regional climate model (RegCM3) with different lateral boundary conditions. Theo Appl Climatol 98:293-314. doi:10.1007/s00704-009-0110-4

Sylla MB, Coppola E, Mariotti L, Giorgi F, Ruti PM, Dell'Aquila A, Bi X (2010) Multiyear simulation of the African climate using a regional climate model (RegCM3) with the high resolution ERAinterim reanalysis. Climate Dyn 35:231-247. doi:10.1007/ s00382-009-0613-9

Tchotchou LAD, Kamga FM (2010) Sensitivity of the simulated African monsoon of summers 1993 and 1999 to convective parameterization schemes in RegCM3. Theor Appl Climatol 100:207-220. doi:10.1007/s00704-009-0181-2
Uppala SM, Kallberg PW, Simmons AJ, Andrae U, Bechtold VD, Fiorino M, Gibson JK, Haseler J, Hernandez A, Kelly GA, Li X, Onogi K, Saarinen S, Sokka N, Allan RP, Andersson E, Arpe K, Balmaseda MA, Beljaars ACM, Van De Berg L, Bidlot J, Bormann N, Caires S, Chevallier F, Dethof A, Dragosavac M, Fisher M, Fuentes M, Hagemann S, Holm E, Hoskins BJ, Isaksen L, Janssen PAEM, Jenne R, McNally A, Mahfouf JF, Morcrette JJ, Rayner NA, Saunders RW, Simon P, Sterl A, Trenberth KE, Untch A, Vasiljevic D, Viterbo P, Woollen J (2005) The ERA-40 re-analysis. Quart J Roy Meteor Soc 131:2961-3012

Yuan X, Xie Z-H, Zheng J, Tian X-J, Yang Z-L (2008) Effects of water table dynamics on regional climate: a case study over east Asian monsoon area. J Geophys Res 113:D21112. doi:10.1029/ 2008JD010180

Zakey AS, Solmon F, Giorgi F (2006) Development and testing of a desert dust module in a regional climate model. Atmos Chem Phys 6:4687-4704

Zeng X, Zhao M, Dickinson RE (1998) Intercomparison of bulk aerodynamic algorithms for the computation of sea surface fluxes using TOGA COARE and TAO data. J Climate 11:2628-2644 